\title{
An Acoustical Technique for Evaluation of Thermal Insulation
}

Daniel R. Flynn, David J. Evans, and Thomas W. Bartel

\section{U.S. DEPARTMENT OF COMMERCE}

National Institute of Standards and Technology

(Formerly National Bureau of Standards)

National Engineering Laboratory

Center for Manufacturing Engineering

Gaithersburg, MD 20899

April 1989

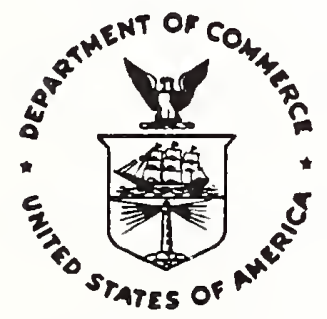

National Bureau of Standards became the National Institute of Standards and Technology on August 23, 1988, when the Omnibus Trade and Competitiveness Act was signed. NIST retains all NBS functions. Its new programs will encourage improved use of technology by U.S. industry.

Prepared for:

U.S. Department of Energy

and

Mineral Insulation Manufacturers Association

\section{U.S. DEPARTMENT OF COMMERCE}

Robert Mosbacher, Secretary

NATIONAL INSTITUTE OF STANDARDS

AND TECHNOLOGY

Raymond G. Kammer, Acting Director 


\section{Table of Contents}

$\underline{\text { Page }}$

List of Figures and Table . . . . . . . . . . . . . . . . . . . . iv

Abstract . . . . . . . . . . . . . . . . . . . . . . 1

1. Introduction . . . . . . . . . . . . . . . . . . . . . . . 1

2. General Technical Approach . . . . . . . . . . . . . . . . . 2

3. Experimental Procedure . . . . . . . . . . . . . . . . . . . 6

3.1 Acoustical Test Chamber . . . . . . . . . . . . . . . 6

3.2 Instrumentation . . . . . . . . . . . . . . . . . . . . . . 9

3.3 Test Procedures . . . . . . . . . . . . . . . . . . . . 11

3.4 Test Samples. . . . . . . . . . . . . . . . . . . . . . . . 12

4. Experimental Results . . . . . . . . . . . . . . . . . . . 13

4.1 Coverage . . . . . . . . . . . . . . . . . . . . . . . . 13

4.2 Thermal Resistance. . . . . . . . . . . . . . . . . . 27

5. Prospects for Field Use. . . . . . . . . . . . . . . . . . . . . 27

6. Conclusions. . . . . . . . . . . . . . . . . . . . . . . . . . . . . 38

7. Acknowledgments . . . . . . . . . . . . . . . . . . . . 39

8. References .. . . . . . . . . . . . . . . . . . 40

\section{List of Figures}

Fig. 1 Instantaneous sound pressure (arbitrary units) versus time for a $40-\mathrm{kHz}$ sine wave

Fig. 2 Conceptual schematic of an acoustic plane wave traveling from a sound source through a porous insulation to a sound receiver. . 7

Fig. 3 Schematic drawing of a compact source projecting sound downward to a parabolic reflector, upward through the sample to another parabolic reflector, and then cownward to a measuring microphone

Fig. 4 Photograph of the test chamber with a sample basket installed. . . 8

Fig. 5 Lower half of the test chamber showing the loudspeaker, the lower reflector, and the sound-absorbing wedges 
Fig. 6 Central portion of the test chamber showing the microphone, the region where the sample basket is installed, the wires that support the sample basket, and the top of the downward-facing loudspeaker

Fig. 7 An example data set of sound insertion loss versus frequency for the 1/3-octave bands with center frequencies from 2.5 to $25 \mathrm{kHz}$

Fig. 8 Measured coverage versus sound insertion loss at $10 \mathrm{kHz}$ for the bonded fiberglass samples (both the blanket and the blown materials)

Fig. 9 Measured coverage versus sound insertion loss at $10 \mathrm{kHz}$ for the blown unbonded fiberglass samples

Fig. 10 Measured coverage versus sound insertion loss at $10 \mathrm{kHz}$ for the blown rockwool samples

Fig. 11 Measured coverage versus sound insertion loss at $10 \mathrm{kHz}$ for the blown cellulose samples

Fig. 12 Percentage change in insertion loss, plotted versus sound frequency, due to compressing a blown bonded fiberglass sample to two different thicknesses

Fig. 13 Percentage change in insertion loss, plotted versus sound frequency, due to compressing a blown unbonded fiberglass sample to two different thicknesses

Fig. 14 Percentage change in insertion loss, plotted versus sound frequency, due to compressing a blown rockwool sample to two different thicknesses

Fig. 15 Percentage change in insertion loss, plotted versus sound frequency, due to compressing a blown cellulose sample to two different thicknesses

Fig. 16 Measured coverage plotted versus predicted coverage for the blown fiberglass samples, both bonded and unbonded.

Fig. 17 Measured coverage plotted versus predicted coverage for the blown rockwool samples. The prediction equation was of the form of Eq. (7)

Fig. 18 Measured coverage plotted versus predicted coverage for the blown rockwool samples. The prediction equation is discussed in the text 
Fig. 19 Thermal conductivity versus installed density for the two types of blown fiberglass material

Fig. 20 Thermal conductivity versus installed density for blown

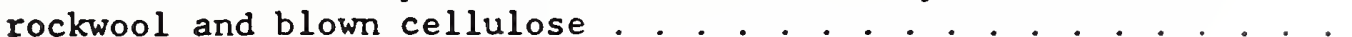

Fig. 21 Thermal resistance versus sound insertion loss, at $10 \mathrm{kHz}$, for the blown bonded and unbonded fiberglass samples . . . . . .

Fig. 22 Thermal resistance versus sound insertion loss, at $10 \mathrm{kHz}$, for the blown rockwool and cellulose samples . . . . . . . . . .

Fig. 23 Thermal resistance computed from density and thickness versus thermal resistance predicted from sound insertion loss and thickness for the blown bonded and unbonded fiberglass samples . . 32

Fig. 24 Thermal resistance computed from density and thickness versus thermal resistance predicted from sound insertion loss and thickness for the blown rockwool samples... . . . . . . . . .

Fig. 25 Thermal resistance computed from density and thickness versus thermal resistance predicted from sound insertion loss and thickness for the blown cellulose samples... . . . . . . . . . . 34

Fig. 26 One experimental configuration for field measurements of the coverage or thermal resistance of blown-in-place attic insulation..

Fig. 27 Experimental configuration for field measurements of the density or thermal conductivity of blown-in-place attic insulation when it is not practical to enter the attic space... . . . . . . . 36

\section{List of Tables}

Table 1 Thickness, coverage, and density of the test samples . . . . . . 14 


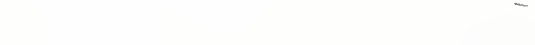




\section{Abstract}

A laboratory apparatus has been constructed that enables rapid measurement of the sound insertion loss of a sample of insulation as a function of frequency. An extensive series of measurements of the sound insertion losses associated with blown samples of fiberglass, rockwool, and cellulose has been completed; the results of these acoustical measurements are highly correlated with coverage (mass per unit area) and thermal resistance ( $R$-value). An investigation is planned to extend the acoustical techniques used in the laboratory apparatus to in-situ determination of the sound transmission loss through thermal insulation installed in attics. Two possible approaches to such field measurements are described.

KEY YORDS: acoustics, attic insulation, heat flow, heat transfer, insulation, non-destructive evaluation, non-destructive testing, sound attenuation, sound propagation, thermal conductivity, thermal insulation, thermal resistance.

\section{Introduction}

There is convincing evidence that the customer may not always be getting his money's worth when he purchases blown-in-place attic insulation, either because the insulation is not applied properly or because the quantity of insulation delivered is less than that purchased. In 1982, for example, the Florida state attorney's office tested 639 homes and found [1] that about 70 percent of the houses insulated by some contractors had less than 90 percent of the insulation claimed to have been installed. An investigation of an insulation certification program by the state of Georgia found [2] that over two-thirds of the "certified" homes actually had less than 90 percent of the required insulation. In addition to the customer being short-changed at the time of purchase, the failure to provide the specified amount of insulation leads to higher fuel bills over the life of the building. The overall economic implications of inadequate insulation of attics are believed to be very significant.

The present procedure for measuring the quantity of insulation installed in an attic is to send one or more workers into the attic to measure the thickness of the insulation, using a ruler, and to measure the density of the insulation, using a circular cutter [3] to acquire samples for weighing. This procedure is costly, in terms of the labor requirements, and destructive, in terms of disruption of the insulation.

Ideally, one would like to use a measurement technique that directly indicates the thermal performance of the installed insulation. Unfortunately, a review of possible thermal techniques for making such a measurement indicates that direct measurement of thermal performance poses several problems. Thermal resistance measurements inherently involve measurement of a heat flux. For large thicknesses of attic insulation, the heat fluxes are very small and difficult to measure accurately in the field. The problem is compounded by the difficulty of evaluating the influence of heat flows - along the ceiling, through framing members, and, most importantly, to or from the attic space and 
to or from the rooms beneath the attic - that do not pass through the attic insulation. Furthermore, the time constants involved in direct measurement of the thermal resistance of installed attic insulation could be many hours.

In December, 1984, the Mineral Insulation Manufacturers Association (MIMA) informed [4] the National Institute of Standards and Technology (NIST), then known as the National Bureau of Standards, that "...there is a national need to develop a field measurement technique to determine the installed loose fill Rvalues of thermal insulation. Other legal requirements such as the FTC Home Insulation Rule require a reliable measurement technique. The installer, builder, utility, code official and, most importantly, the consumer need a means to measure installed R-values. The technique should be accurate, fast, nondestructive and economical. Recent efforts in the industry, and elsewhere, to devise a measurement technique have not been satisfactory. "MIMA went on to ask NIST to address this measurement need.

Following meetings between MIMA and NIST technical personnel, a "Workshop on New Methods to Measure the R-Value of Thermal Insulation" was held at the National Association of Homebuilders in Washington, D.C., in June of 1985, with approximately 70 people in attendance. At this workshop, there was extensive discussion of the nature of the problem and a general endorsement of the need for improved measurement procedures. NIST staff then described an acoustical technique for indirect measurement of either the coverage (mass per unit area) or the thermal resistance (R-value) of installed attic insulation by passing sound waves through a sample of material and measuring the sound insertion loss (i.e., the decrease in sound pressure level) caused by the insulation. A live demonstration of one simple implementation of this acoustical technique was given at the Workshop. NIST indicated that the development of such a technique as a practical field device would require considerable effort but that the preliminary analysis and results looked quite encouraging.

The present paper (1) describes the acoustic technique that was proposed in 1985 by NIST, (2) presents the results of a pilot study (funded by MIMA, the U.S. Department of Energy, and NIST) to examine the feasibility of this technique for measurement of insulation coverage (or density) and thermal performance, and (3) indicates how this technique could be extended to enable practical field measurements of the adequacy of installed insulation.

\section{General Technical Approach}

When a sound wave passes through a porous material, such as loose-fill insulation, the sound wave undergoes both amplitude attenuation and a phase shift that depend on the nature of the material and on the frequency of the incident sound wave. For example, the sound attenuation characteristics of fibrous materials are dependent upon, in addition to the frequency of the sound wave, the type of fiber, the distribution of fiber diameters, the surface condition of the fibers, the binder, the installed density, and the type and density of the gas filling the pores of the material. There is an extensive literature devoted to theoretical and empirical relationships between these factors and the sound attenuation characteristics of fibrous materials. The same factors 
which affect the propagation of sound in a fibrous material also affect thermal conductivity, and hence $R$-value.

The time-dependent sound pressure associated with an ideal plane acoustic wave traveling in the positive $\mathrm{x}$-direction in a porous medium can be expressed as

$$
p=p(x, t)=p(0, t) \exp (-\gamma x),
$$

where $p(0, t)$ is the sound pressure that would exist, independent of position, in the absence of attenuation, $t$ is time, and $\gamma$ is the complex propagation coefficient, which can be written as

$$
\gamma=\alpha+j \beta
$$

where the real part $\alpha$ is called the attenuation coefficient and the imaginary part $\beta$ is the phase coefficient. The attenuation coefficient, which is a property of the porous medium and of the frequency of the sound wave, determines the decay of the sound pressure with distance in the medium. The phase coefficient, which also is a property of the medium and the sound frequency, describes the speed of sound propagation through the medium.

Figure 1 illustrates the behavior described by Eq. (1). The solid curve represents the sound pressure observed when an acoustic sine wave passed through air from a 40-kilohertz source to a receiving microphone. The curve designated by long dashes represents the received sound pressure when a sample of R-11 fiberglass insulation was interposed between the source and the receiving microphone, while the curve shown as short dashes illustrates the received sound pressure when two pieces of $\mathrm{R}-11$ insulation were interposed. It is seen that as additional absorptive material is placed in the sound path, the amplitude of the sinusoidal sound wave decreases, the change being described by the attenuation coefficient $(\alpha)$, and the phase of the sine wave is shifted, by an amount described by the phase coefficient $(\beta)$.

The mean-square sound pressure, which is independent of time, at the position $x$ is given by

$$
p^{2}=p_{o}^{2} \exp (-2 \alpha x) \text {, }
$$

where $\mathrm{Po}^{2}$ is the mean-square value of $\mathrm{p}^{2}$ at $\mathrm{x}=0$. The sound insertion loss, defined as the decrease in sound pressure level in decibels (with attenuation present) relative to the sound pressure level that would exist if there were no attenuation, is

$$
D=-10 \log _{10}\left(p^{2} / p_{o}^{2}\right)=-10 \log 10[\exp (-2 \alpha x)]=8.686 \alpha x .
$$

Thus, the sound insertion loss is proportional to the product of the attenuation coefficient and the sample thickness.

Delaney and Bazley [5] have developed empirical relationships expressing the attenuation and phase coefficients of fibrous absorbent materials as simple power-law functions of the ratio of the sound frequency divided by the specific flow resistance of the material. Bies [6] has presented an empirical relation- 


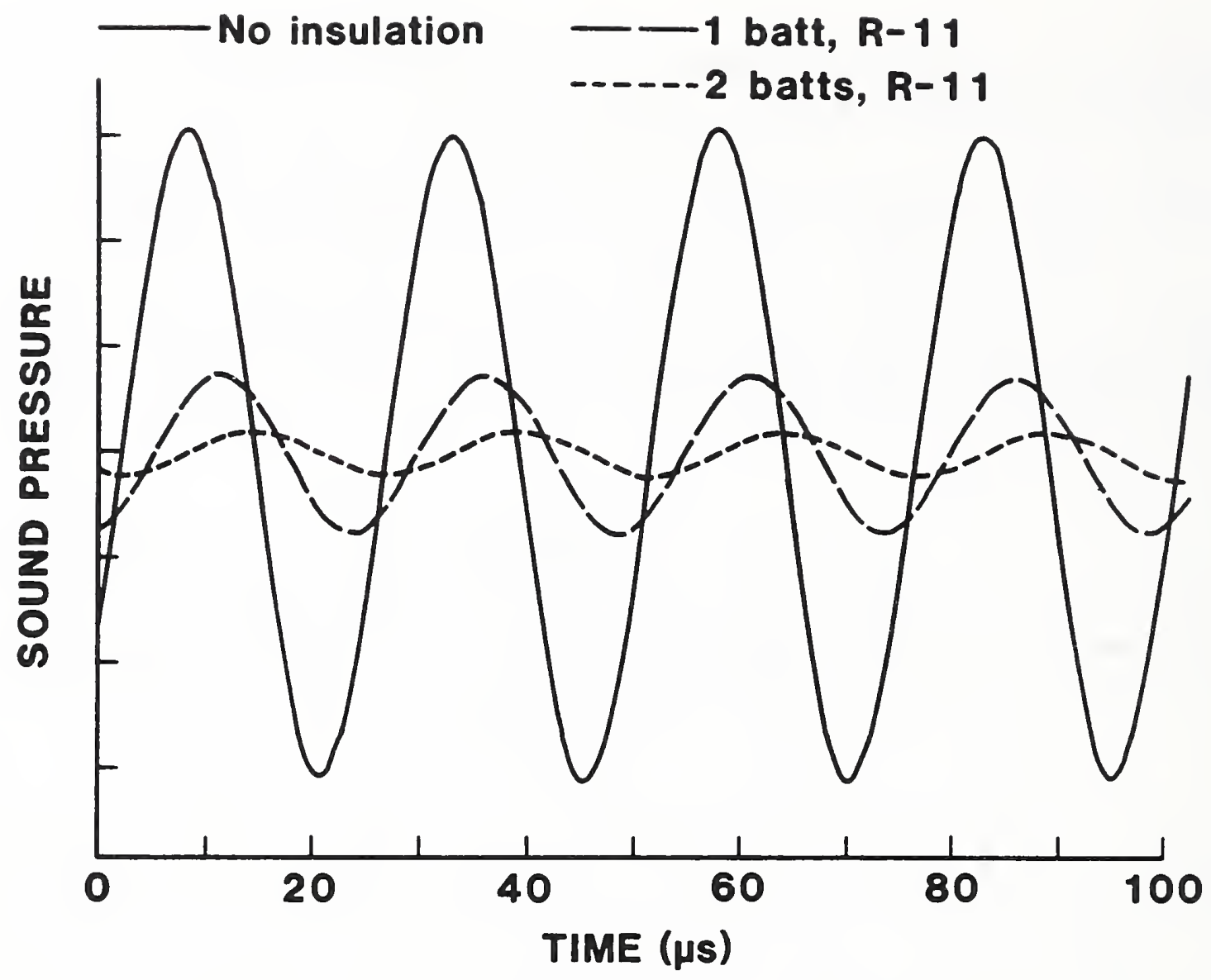

Fig. 1 Instantaneous sound pressure (arbitrary units) versus time for a $40-\mathrm{kHz}$ sine wave. The solid line corresponds to propagation through air. The long-dash line illustrates the attenuation and the phase shift due to interposing a $9-\mathrm{cm}$ thick sample of fiberglass ( 1 R-11 batt) between the source and the receiver, while the short-dash line indicates the sound pressure with $18 \mathrm{~cm}$ (2 R-11 batts) of insulation in place.

ship giving the specific flow resistance of fiberglass products in terms of the fiber diameter and the installed density of the material. Combining Delaney and Bazley's expressions with the Bies relationship enables us, for randomly oriented fibrous material, to express the attenuation and phase coefficients in terms of the installed density, $\rho$, of the insulation, the average fiber diameter, $d$, and the sound frequency, $f$. The resultant expression for the attenuation coefficient is

$$
a=a_{0} \cdot\left(\frac{\rho}{\rho_{0}}\right)^{\mu} \cdot\left(\frac{d_{0}}{d}\right)^{\nu} \cdot\left(\frac{f}{f_{0}}\right)^{\xi},
$$

where $\alpha_{0}$ is a reference attenuation coefficient corresponding to the values $\rho=$ $\rho_{0}, d=d_{0}$, and $f=f_{0}$. The three exponents in Eq. (5) have. the approximate 
values $\mu \approx 0.9, \nu \approx 1.2$, and $\xi \approx 0.4$. These exponents vary somewhat for different materials. The phase coefficient will not be discussed further in the present paper.

Although there may be a considerable range of fiber diameters within a given batch of fibrous insulation, a representative fiber diameter may be determined.

Since the sound frequency can be fixed experimentally, one can take $d=d_{0}, f=$ $f_{O}$, and Eq. (5) yields the following simple relationship between the attenuation coefficieat and the installed density of the insulation:

$$
\alpha=\alpha_{0} \cdot\left(\begin{array}{l}
\rho \\
\rho_{0}
\end{array}\right)^{\mu} \text {. }
$$

Thus, for a given material it is not necessary to know $\nu$ and $\xi$. The coverage, or mass per unit area, of installed insulation in an attic is given by $W=\rho l$, where $\ell$ is the thickness of the insulation. Combining this equation with Eqs. (4) and (6), the coverage is related to the sound insertion loss by the expression

$$
\mathrm{W}=\mathrm{K} \cdot \mathrm{D}^{\eta} e^{1-\eta},
$$

where $\eta=1 / \mu$ and $\mathrm{K}$ is a material-dependent proportionality constant. The parameter $\eta$ will have a value not too different from unity so that the sample thickness, $\ell$, need not be known very accurately in order to use Eq. (7). For the special case where $\eta=1$, Eq. (7) reduces to simply $W=K$. D, i.e., the coverage is proportional to the sound insertion loss.

It is well known that the effective thermal conductivity of a given loosefill insulating material depends upon the installed density of that material. For mineral fiber insulations, the effective thermal conductivity, $\lambda$, of relatively thick insulation can be represented in terms of the installed density, $\rho$, of the material by an equation of the form

$$
\lambda=\mathrm{A}+\mathrm{B} \rho+\mathrm{C} / \rho,
$$

where $A, B$, and $C$ are constants, with (approximately) A representing the thermal conductivity of the gas (air) filling the insulation, $B \rho$ representing heat conduction through the fibers and the interaction of that conduction with the surrounding gas, and $\mathrm{C} / \mathrm{P}$ representing the radiative heat transfer through the porous insulation.

The thermal resistance of the sample can be expressed as

$$
\mathrm{R}=\frac{\ell}{\lambda}=\frac{\mathrm{W}}{\mathrm{A} \rho+\mathrm{B} \rho^{2}+\mathrm{C}} .
$$

If the density of the sample is constant, so is the denominator of Eq. (9) and the thermal resistance of the sample is proportional to the coverage. Thus, by way of Eq. (7), the thermal resistance can be expressed in terms of the sound insertion loss and the sample thickness. For the more general case where the installed density is variable and unknown, the density can be estimated from the sound insertion loss and the thickness. Dividing both sides of Eq. (7) by $\ell$ yields, since $W=\rho \ell$, 


$$
\rho=K \cdot(D / \ell)^{\eta}
$$

this value of $\rho$ can be used to compute the denominator of Eq. (9). Thus if the functional relationship between thermal conductivity and density is known (i.e., if $A, B$, and $C$ are known for the example above), the thermal resistance can be obtained from the measured sound insertion loss and the approximate sample thickness.

\section{Experimental Procedure}

\subsection{Acoustical Test Chamber}

The apparatus designed and constructed for the acoustical measurements is conceptually similar to a guarded hot plate apparatus used for thermal resistance measurements. Ideally, as indicated in Fig. 2, a sound source projects a plane collimated sound wave upward through the sample to a receiver above the sample. Measurement of the sound levels at the receiver with the sample present and with the sample absent enables calculation of the sound insertion loss (see Eq. (4)). This experimental configuration was achieved using the components illustrated in Fig. 3. The sound source consisted of a small loudspeaker located at the focal point of an upward-facing parabolic reflector used to produce an approximately collimated beam of sound. The insulation sample was held in a wood-sided basket with a screen bottom to allow passage of the sound wave. The sound receiver was a condenser microphone located at the focal point of a downward-facing parabolic reflector.

The test chamber is shown to the right of the photograph in Fig. 4. The two parabolic reflectors, the source transducer (loudspeaker), the measuring microphone, and a support shelf for the sample baskets were housed inside a cabinet approximately $0.9 \mathrm{~m}$ by $0.9 \mathrm{~m}$ by $2.1 \mathrm{~m}$ high. The interior walls of the cabinet were lined with $20-\mathrm{cm}$ by $20-\mathrm{cm}$ by $25 \mathrm{-cm}$ deep wedges constructed from fiberglass board (Owens-Corning Fiberglas Type 703, nominally of $50 \mathrm{~kg} / \mathrm{m}^{3}$ density), except for a nominally $40-\mathrm{cm}$ high section above the sample-basket support shelf (to allow room inside the enclosure for the insertion of a sample basket or baskets) and certain areas of the walls, e.g., corners, which were not completely covered by the wedges due to geometrical constraints - these portions were covered with a $5-\mathrm{cm}$ or a $15-\mathrm{cm}$ thick layer of fiberglass board, as appropriate. 1 The interiors of the floor and ceiling of the cabinet were covered with a $5-\mathrm{cm}$ layer of fine-fiberglass aircraft insulation (Owens-Corning Fiberglas Type PF-105), which has a much higher sound attenuation coefficient than does the fiberglass board used for lining the rest of the cabinet.

${ }^{1}$ Certain trade names and company products are identified in this report in order to specify adequately the experimental procedures that were followed. In no case does such identification imply recommendation or endorsement by the National Institute of Standards and Technology, nor does it imply that the products identified are necessarily the best available for the purpose. 


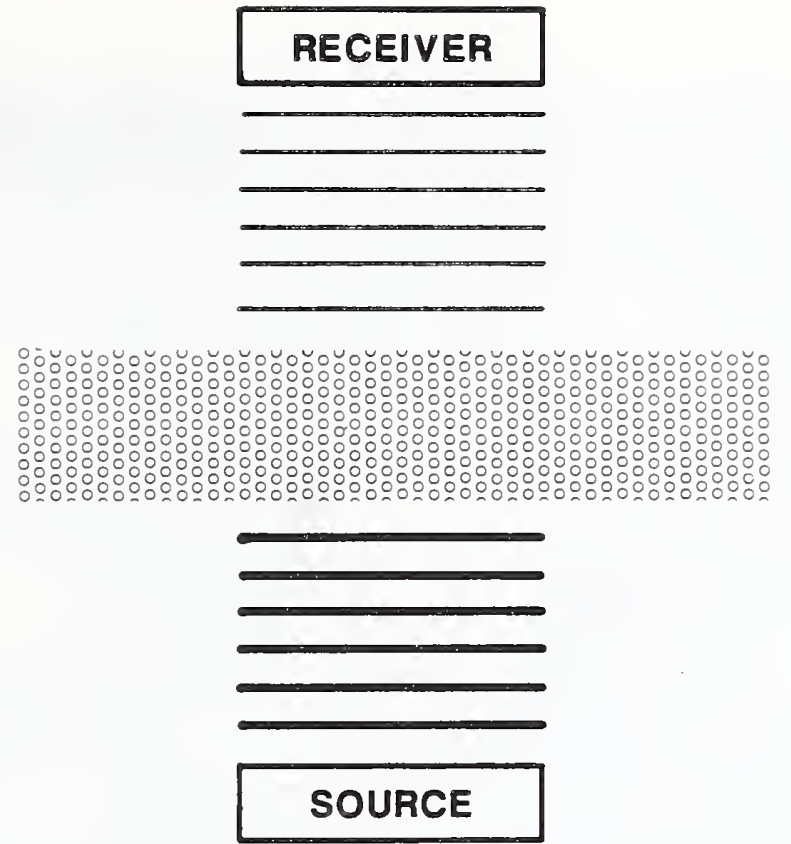

Fig. 2 Conceptual schematic of an acoustic plane wave traveling from a sound source through a porous insulation to a sound receiver.

\section{Parabolle reflector}

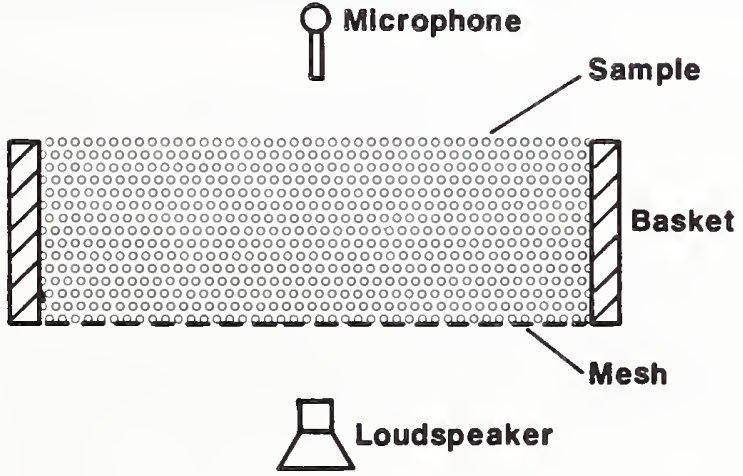

Fig. 3 Schematic drawing of a compact source projecting sound downward to a parabolic reflector, upward through the sample to another parabolic reflector, and then downward to a measuring microphone. 


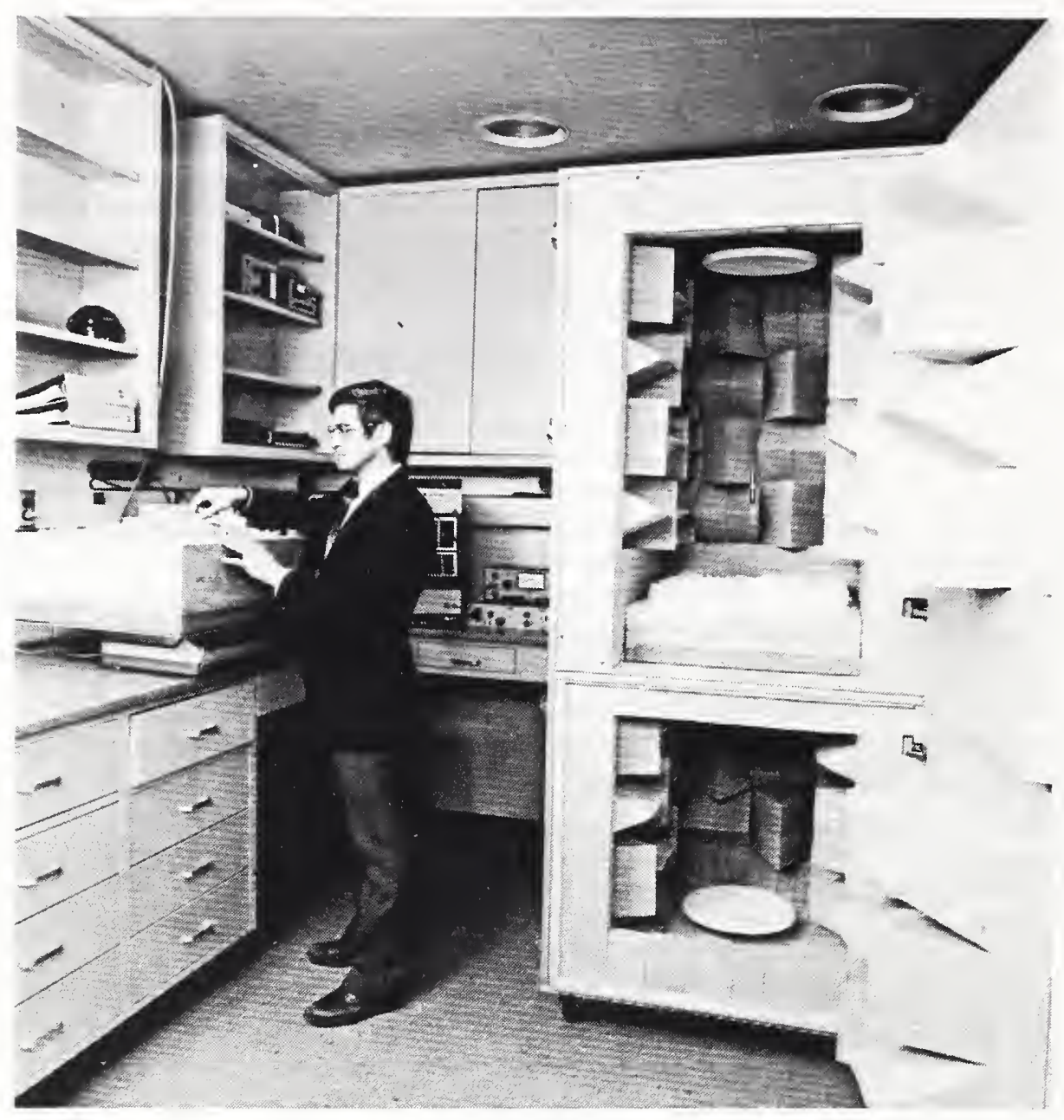

Fig. 4 Photograph of the test chamber with a sample basket installed. The scientist is measuring the thickness of another sample, which is resting on a digital balance.

The sample baskets, one of which is shown installed in the test chamber in Fig. 4, had nominal inside dimensions of 53 by $53 \mathrm{~cm}$ and nominal heights of 15 or 23 $\mathrm{cm}$. The baskets were constructed from $1.3-\mathrm{cm}$ thick unfinished plywood, were open at the top, and had nylon window screen stretched across the bottom to hold the material in the baskets (the baskets were transported with a piece of fiberboard underneath to prevent the screen from sagging in the center of the basket and thus possibly altering the distribution of material within the basket). The inside of each of the walls of the baskets was lined with $2.5-\mathrm{cm}$ thick $50 \mathrm{~kg} / \mathrm{m}^{3}$ fiberglass board insulation to reduce acoustical reflections within the baskets during testing. The sides of the baskets were held together with glue and metal finishing nails, and the nylon screen was attached to the outside of the walls of the baskets with metal staples and nylon tape.

Figure 5 is a close-up photograph of the lower half of the test chamber, showing the loudspeaker, the lower parabolic reflector, and a better view of the sound absorbing wedges used to minimize unwanted sound reflections inside 


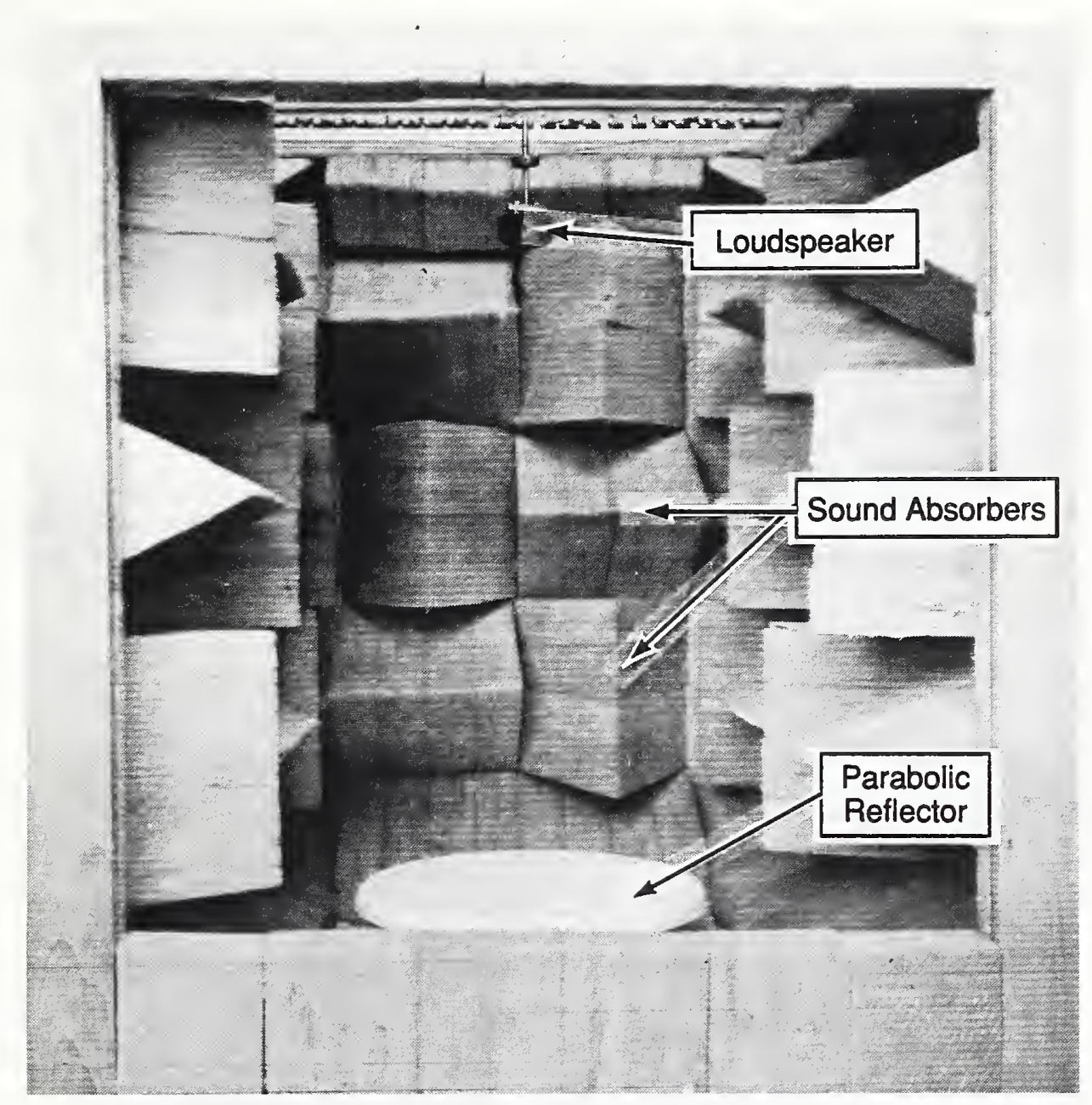

Fig. 5 Lower half of the test chamber showing the loudspeaker, the lower reflector, and the sound-absorbing wedges.

the chamber. Figure 6 provides a view of the portion of the test chamber where the sample baskets are installed in the region between the supporting wires and the height at which the absorbing wedges begin. The supporting wires prevent the nylon screen bottom of the sample basket from sagging. The measuring microphone can be seen near the top of the Fig. 6. The test results given in this paper are very insensitive to loudspeaker and microphone placement.

\subsection{Instrumentation}

The instrumentation used to make the acoustic measurements consisted primarily of a signal generator, filter, and amplifiers to provide the signal to the loudspeaker. A microphone preamplifier, measuring amplifier, and dynamic signal analyzer were used to measure the voltages produced by the signal generator and the measuring microphone. 


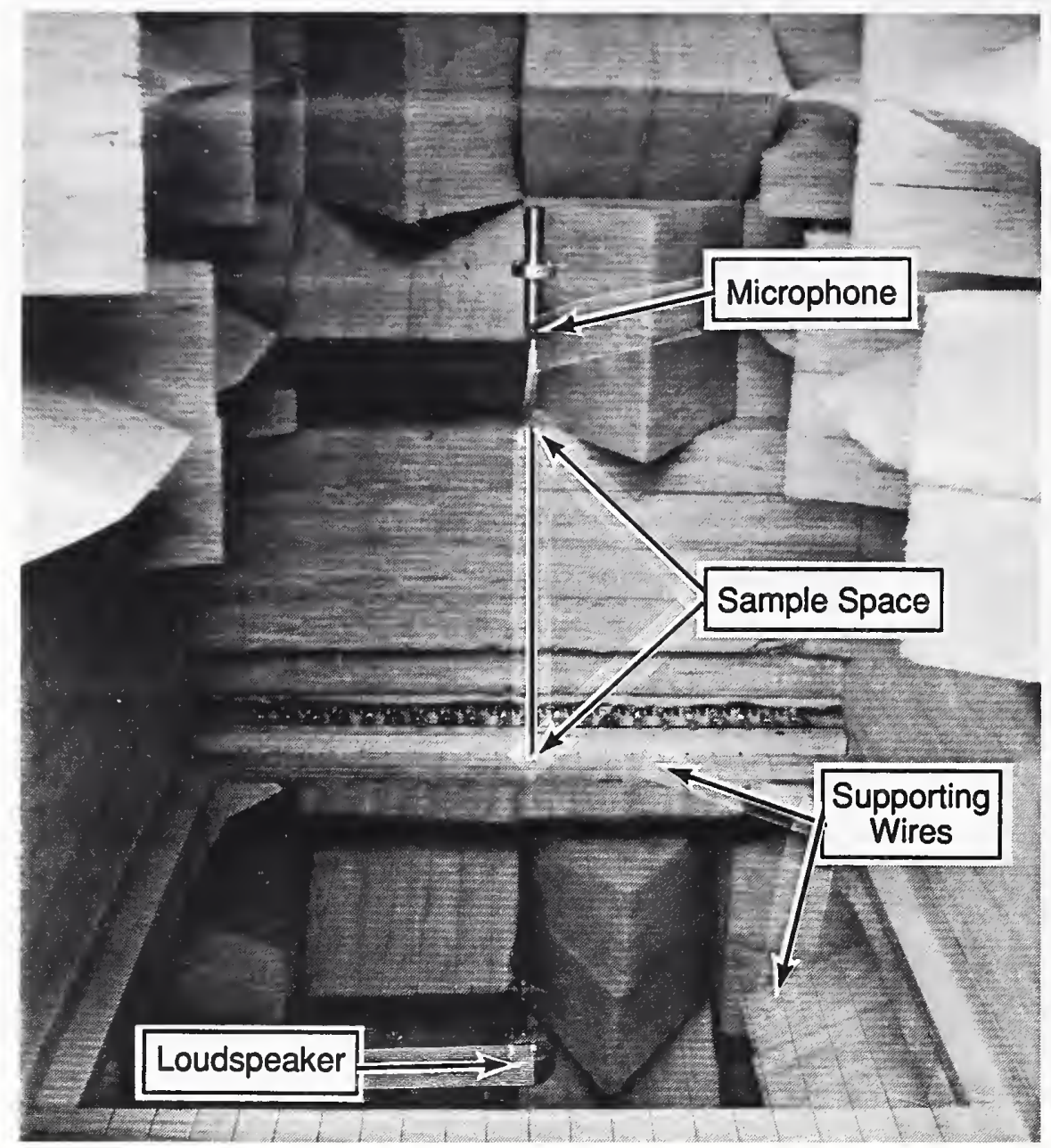

Fig. 6 Central portion of the test chamber showing the microphone, the region where the sample basket is installed, the wires that support the sample basket, and the top of the downward-facing loudspeaker.

The signal used to drive the loudspeaker was a highpass-filtered swept sine wave that was gated to produce a "chirp" of 1-ms duration. The chirp was repeated every $200 \mathrm{~ms}$. The signal was gated such that the frequency sweeps at the output of the signal generator began and ended on a positive-going zerocrossing. A trigger circuit was used to synchronize the signal analyzer with the rest of the measurement instrumentation. The signal generator was comprised of two function generators (Hewlett Packard Model 3314A). The first function generator produced a voltage ramp that was repeated every $200 \mathrm{~ms}$ and drove a voltage-controlled oscillator that was part of a second function generator. The second function generator was set to produce an integral number of cycles within each frequency sweep and then gate "off" until receiving the next trigger from the first function generator. The output of the second function generator was followed by a wide-band amplifier (Hewlett Packard Model 
467A) and high-pass filter (consisting of a $200 \mathrm{pF}$ capacitor in series with the input stage of the amplifier) to shape the spectrum of the "chirp." The filtered waveform of the test signal was amplified by a power amplifier (McIntosh Model 7270) that drove the loudspeaker (Analog and Digital Systems 25-mm dome tweeter, Part No. 206-0114, without protective grid).

The output of the measuring microphone (Bruel \& Kjaer Type 4165 without protective grid) was coupled to a preamplifier (Bruel \& Kjaer Type 2619), power supply (Bruel \& Kjaer Type 2801), and measuring amplifier (Bruel \& Kjaer Type 2606). The gain of the measuring amplifier was adjusted as needed to match the input sensitivity of the signal analyzer. The output signal of the measuring amplifier was time-gated by an electronic switch (General Radio Type 1396-B Tone-Burst Generator) to prevent undesirable acoustic signals (e.g., delayed reflections) from occurring during a measurement period. The electronic switch was triggered by the output of a digital-delay generator (Berkeley Nucleonics Corp. Model 7010) which was adjusted to provide the proper electronic delay to compensate for the acoustic delay in the test chamber.

The signal analyzer (Hewlett Packard Model 5420A) was used in a two-channel mode in which it obtained a transfer function, at $100-\mathrm{Hz}$ intervals up to $25 \mathrm{kHz}$, for the measurement system between the output of the second function generator and the output of the electronic switch following the measuring microphone. The analyzer averaged the results from 100 chirps, or bursts of sound, obtained with and without the test sample being installed in the test chamber, and stored these results. The analyzer was later used to take the complex ratio of the transfer functions obtained with and without the sample present, thus compensating for the frequency response of the transducers and instrumentation. A desktop computer (Hewlett Packard Model 9836A) was used to calculate sound insertion loss, in decibels, and phase shift, in degrees, from the measurement results. A separate computer (IBM Model XT) was used to combine the data so as to obtain the average sound insertion losses for the eleven 1/3-octave band frequencies centered at nominally $2.5,3.15,4,5,6.3$, $8,10,12.5,16,20$, and $25 \mathrm{kHz}$. Figure 7 shows a representative set of such data.

\subsection{Test Procedures}

The test samples were blown into pre-weighed test baskets to the approximate desired test density using an "open blow machine" (Unisul Model Volumatic II No. 1804E2MH) designed specifically for pneumatic application of the materials tested. The baskets of blown insulation were allowed to come to thermal and moisture equilibrium with the air in the laboratory module where the acoustic test apparatus was located. The weight of an empty basket was monitored to enable tracking the change in the tare weight of the baskets due to varying moisture content in the wooden sides of the baskets. Just prior to acoustic testing, the filled basket was weighed and the (adjusted) tare weight subtracted to obtain the mass of insulation material. Fiberglass blankets were tested without baskets and thus their weight was measured directly. The thickness of each test sample was measured at multiple locations using a pinand-disk depth gage and steel rule [7]. The scientist shown in Fig. 4 is beginning to make a thickness measurement while the filled sample basket is located on the digital balance. The coverage $\left[\mathrm{kg} / \mathrm{m}^{2}\right]$ and the installed density 


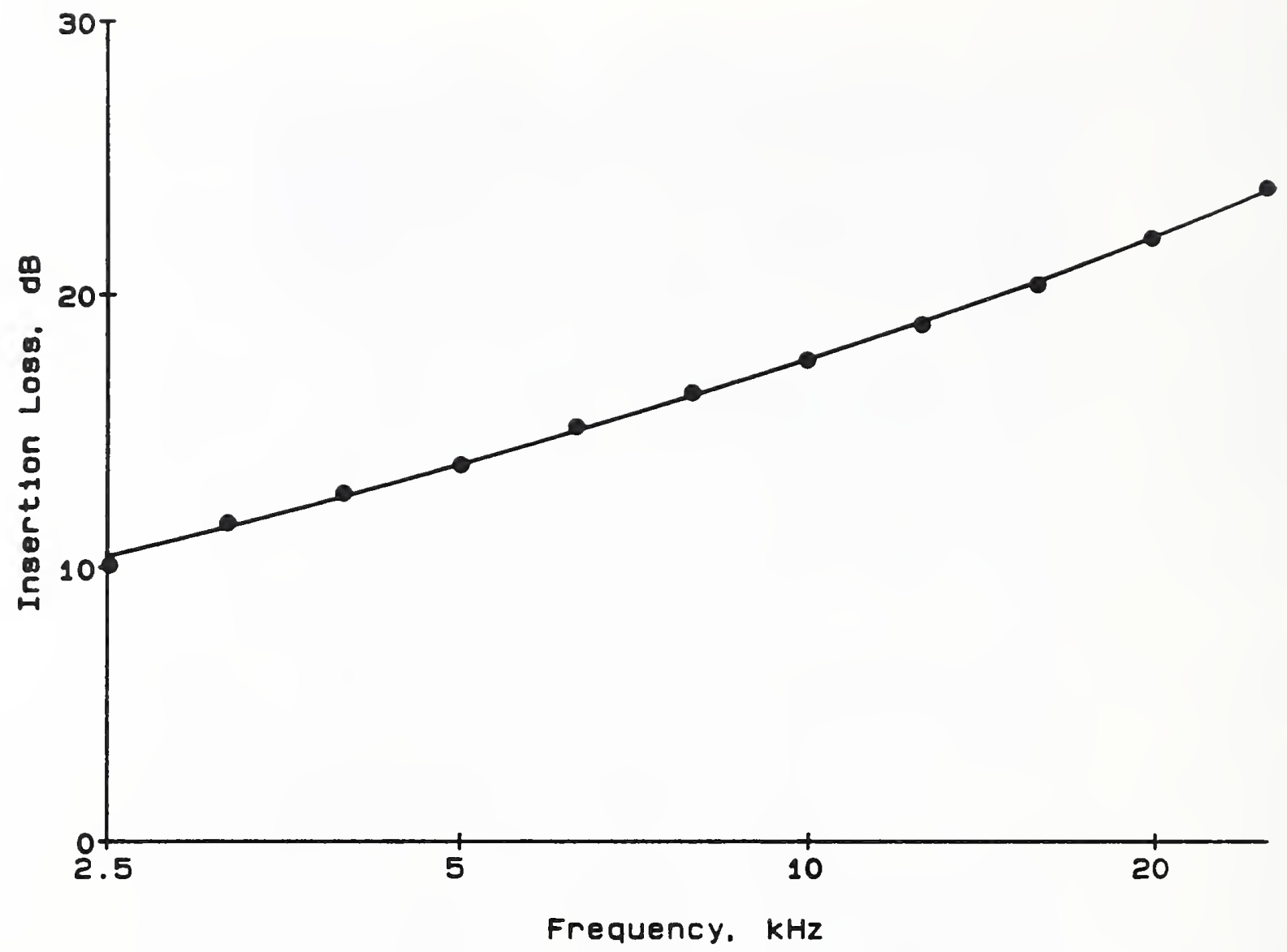

Fig. 7 An example data set of sound insertion loss versus frequency for the $1 / 3$-octave bands with center frequencies from 2.5 to $25 \mathrm{kHz}$. The sample was blown bonded fiberglass with a coverage of $1.84 \mathrm{~kg} / \mathrm{m}^{2}$.

$\left[\mathrm{kg} / \mathrm{m}^{3}\right]$ of each test sample were computed from the mass and average thickness of the sample and the area of the interior of the basket.

After the mass and thickness measurements were completed, the sample was placed in the test chamber and the acoustic measurements carried out using the instrumentation and signal described above. The acoustical measurements required $20 \mathrm{~s}$, of which only $0.1 \mathrm{~s}$ was used to acquire data, the rest of the time being used to assure that the signal captured corresponded to sound that made a single pass through the sample (i.e., contained negligible reflected energy) and to protect the source transducer from excessive power input.

\subsection{Test Samples}

This study benefitted greatly by being able to "piggyback" on the round-robin tests [8] of the apparent thermal conductivity of several loose-fill insulations carried out recently under the auspices of the ASTM C16.30 Task Group on C687 Loose-Fill Testing. Materials from the same lots as those used for this 
round robin were made available to NIST for the acoustic tests described in the present paper. The test materials investigated were a fiberglass blanket (the only material not blown), a bonded fiberglass, an unbonded fiberglass, a rockwool, and a cellulose. The reader is referred to Ref. 8 for more complete descriptions of these materials.

Samples were blown at densities within 10 percent of the target densities for the round robin tests referenced above. Additional samples for this study were intentionally blown to smaller or larger densities than those specified in the round robin instructions. For each of the four blown materials, at least one sample was tested at its as-blown density and then compressed and acoustically measured at two higher densities.

Table 1 gives the thickness, coverage, and density of the samples used for the acoustical measurements reported in this paper. The entries with an asterisk following the sample thickness correspond to further compression of the proceeding sample. The fiberglass blanket samples of different thicknesses were obtained by stacking individual blankets. The samples with a dagger following the thickness correspond to the two previous sample boxes being stacked one upon the other in the acoustic test chamber.

\section{Experimental Results}

Acoustical data were taken over the frequency range from 2.5 to $25 \mathrm{kHz}$. However, with the exception of the data on the direct effects of sample compression, shown in Figs. $12-15$ below, only data at $10 \mathrm{kHz}$ are included in the present paper. This frequency was selected to enable treating the various materials and thicknesses on a common basis.

\subsection{Coverage}

Figure 8 shows the measured values of coverage (mass per unit area in the test basket) plotted versus the measured sound insertion loss at $10 \mathrm{kHz}$ for the samples of bonded fiberglass blanket and of blown bonded fiberglass. The straight lines drawn from the origin through the data are seen to fit the experimental data very well and the slopes of the two lines only differ by 2.4 percent. Figure 9 shows the same quantities plotted for the blown unbonded fiberglass. The data are reasonably well fitted by the straight line but not so well as in the previous figure. The three data points for a coverage of $1.99 \mathrm{~kg} / \mathrm{m}^{2}$ (see Table 1) correspond to the same sample at three different thicknesses, obtained by further compression; the fact that the same coverage does not produce the same sound insertion loss indicates that the coverage is not simply proportional to the sound insertion loss so that, in $\mathrm{Eq}$. ( 7 ), $\eta$ is not equal to one. It should also be noted that the slope of the line in Fig. 9 is very different from the slopes of the lines in Fig. 8. For a given coverage, the finer-fiber unbonded glass produces almost twice the sound attenuation produced by the larger-fiber bonded material.

Figure 10 is a plot of the coverage of blown rockwool plotted versus the measured sound insertion loss at $10 \mathrm{kHz}$. There is considerable scatter in the 
Table 1 Thickness, coverage, and density of the test samples. (The tabulated densities may, due to rounding errors, differ slightly from values computed from the tabulated thickness and coverages.)

\begin{tabular}{|c|c|c|c|}
\hline Sample Material & $\begin{array}{c}\text { Thickness } \\
\text { m }\end{array}$ & $\begin{array}{c}\text { Coverage } \\
\mathrm{kg} / \mathrm{m}^{2}\end{array}$ & $\begin{array}{c}\text { Density } \\
\mathrm{kg} / \mathrm{m}^{3}\end{array}$ \\
\hline Fiberglass blanket & $\begin{array}{l}0.278 \\
0.248 \\
0.310 \\
0.184\end{array}$ & $\begin{array}{l}3.11 \\
2.78 \\
3.44 \\
2.11\end{array}$ & $\begin{array}{l}11.2 \\
11.2 \\
11.1 \\
11.5\end{array}$ \\
\hline Blown bonded glass wool & $\begin{array}{l}0.184 \\
0.186 \\
0.370 \dagger \\
0.233 \\
0.183 x \\
0.128 x \\
0.188 \\
0.220\end{array}$ & $\begin{array}{l}1.84 \\
1.87 \\
3.70 \\
1.73 \\
1.73 \\
1.73 \\
1.37 \\
2.35\end{array}$ & $\begin{array}{r}9.9 \\
10.1 \\
10.0 \\
7.5 \\
9.5 \\
13.6 \\
7.3 \\
10.7\end{array}$ \\
\hline Blown unbonded glass wool & $\begin{array}{l}0.169 \\
0.168 \\
0.337 \dagger \\
0.229 \\
0.178 \pi \\
0.119 x \\
0.191 \\
0.207\end{array}$ & $\begin{array}{l}1.69 \\
1.75 \\
3.44 \\
1.99 \\
1.99 \\
1.99 \\
1.52 \\
2.14\end{array}$ & $\begin{array}{r}10.0 \\
10.4 \\
10.2 \\
8.7 \\
11.2 \\
16.7 \\
7.9 \\
10.4\end{array}$ \\
\hline Blown rockwool & $\begin{array}{l}0.165 \\
0.225 \\
0.180 x \\
0.117 x \\
0.162 \\
0.189 \\
0.184 \\
0.173 \\
0.169\end{array}$ & $\begin{array}{l}5.41 \\
5.44 \\
5.44 \\
5.44 \\
5.39 \\
6.47 \\
6.43 \\
3.69 \\
3.64\end{array}$ & $\begin{array}{l}32.7 \\
24.2 \\
30.2 \\
46.3 \\
33.3 \\
34.3 \\
34.9 \\
21.3 \\
21.5\end{array}$ \\
\hline Blown cellulose & $\begin{array}{l}0.169 \\
0.199 \\
0.183 \\
0.188 \\
0.147 x \\
0.115 *\end{array}$ & $\begin{array}{l}7.15 \\
8.04 \\
6.94 \\
7.79 \\
7.79 \\
7.79\end{array}$ & $\begin{array}{l}42.4 \\
40.3 \\
37.9 \\
41.4 \\
52.9 \\
67.6\end{array}$ \\
\hline
\end{tabular}

$\dagger \quad$ Two samples stacked
$* \quad$ Compressed 


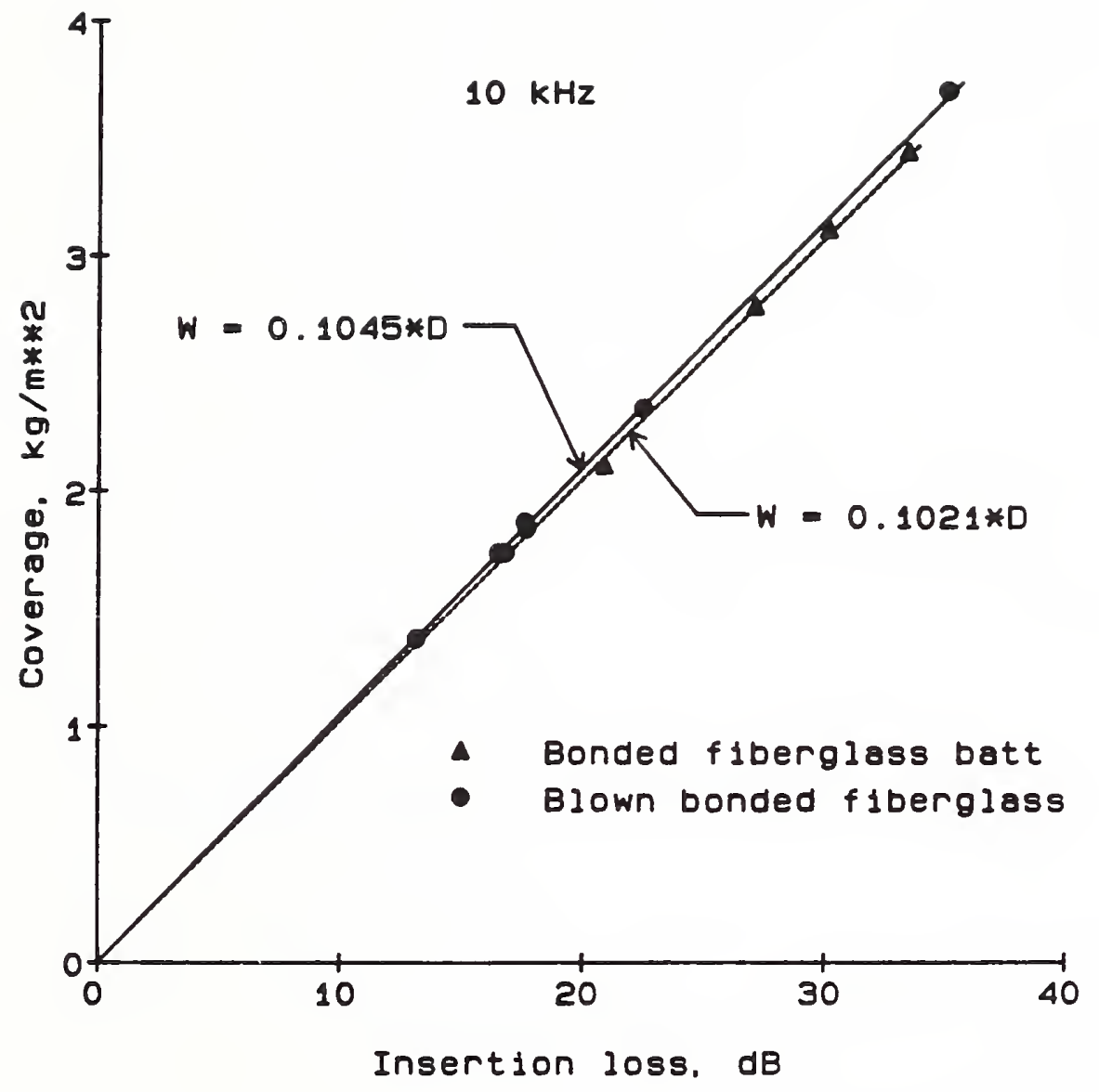

Fig. 8 Measured coverage versus sound insertion loss at $10 \mathrm{kHz}$ for the bonded fiberglass samples (both the blanket and the blown materials). The equations define the leastsquares straight lines fitted to the data and passing through the origin. 


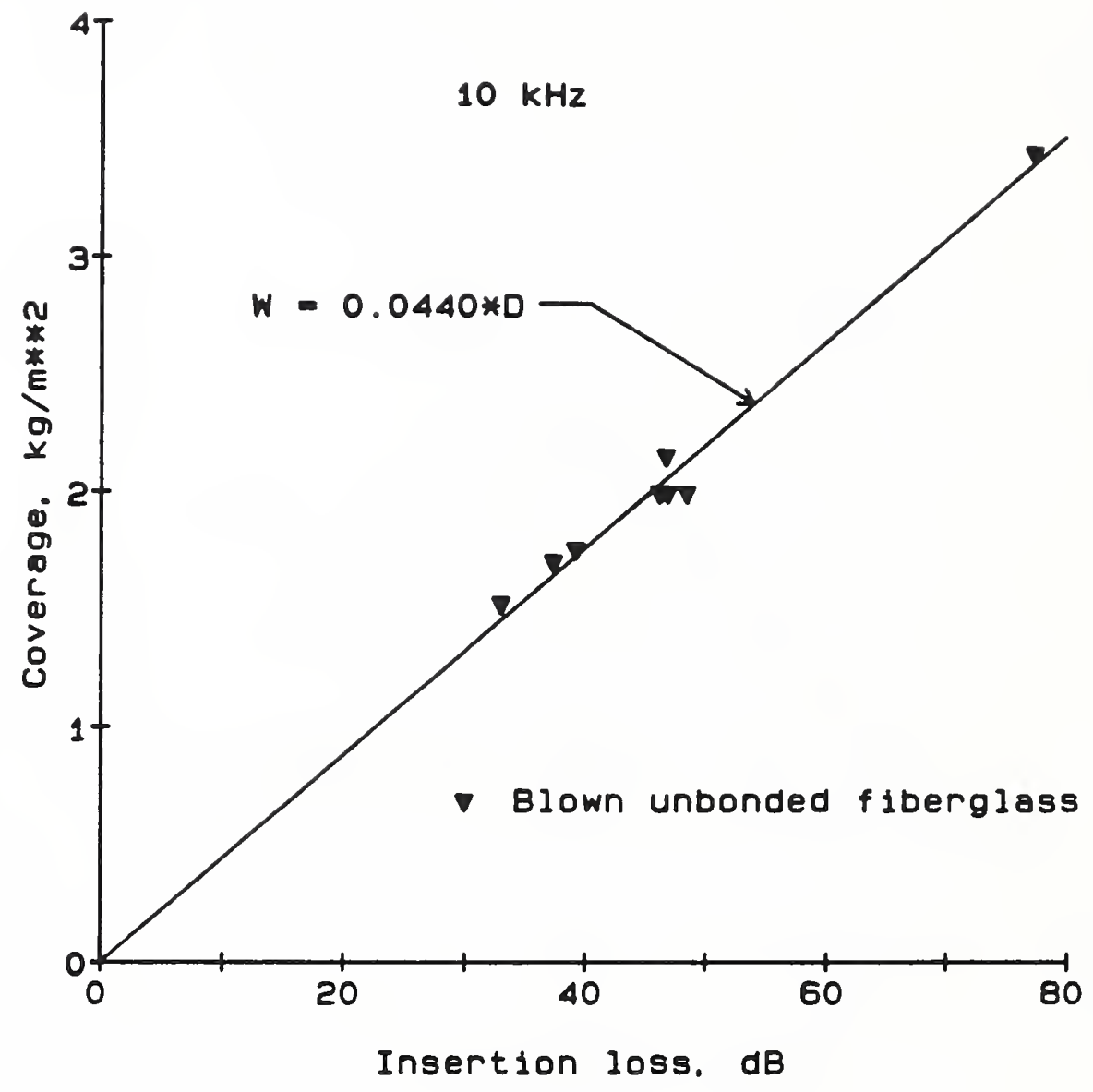

Fig. 9 Measured coverage versus sound insertion loss at $10 \mathrm{kHz}$ for the blown unbonded fiberglass samples. The equation defines the least-squares straight line fitted to the data and passing through the origin. 


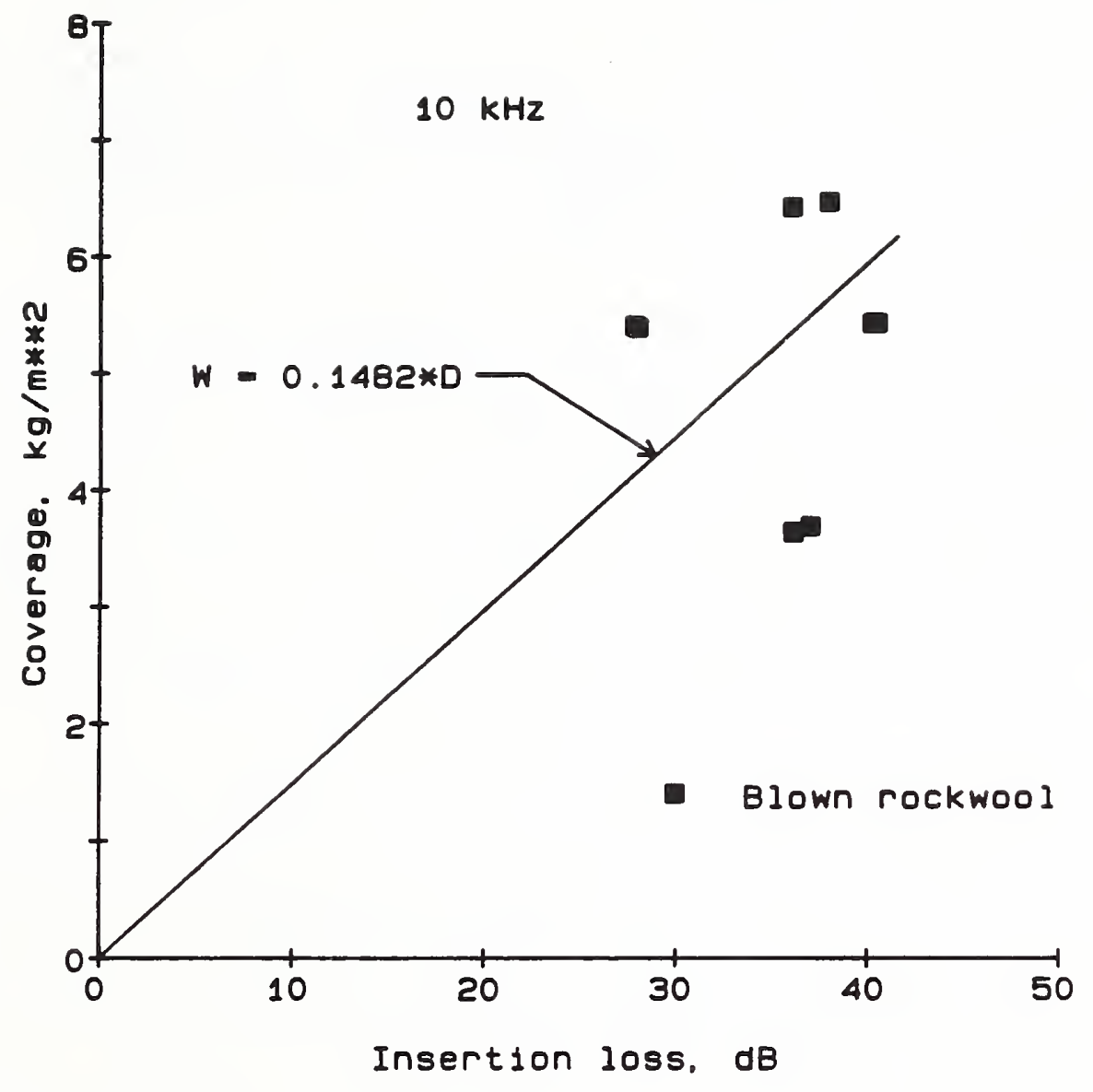

Fig. 10 Measured coverage versus sound insertion loss at $10 \mathrm{kHz}$ for the blown rockwool samples. The equation defines the least-squares straight line fitted to the data and passing through the origin. 
results and the data deviate considerably from the straight line fitted to them. This scatter should not, however, be too surprising. Rockwool typically contains a significant percentage of "shot" and fused fibers that are too large to contribute to sound absorption but which may constitute up to 40 percent of the mass. One would expect to have statistical variations in the percentage of shot in different samples, even from the same lot of material. Furthermore, when samples of different density are produced by differences in blowing technique, one would expect systematic variations in shot content.

The coverage-versus-insertion loss data for cellulose are shown in Fig. 11. The sound insertion loss at $10 \mathrm{kHz}$ for the highest density sample (the last entry in Table 1) was too high to be measured accurately and hence is not shown in Fig. 11. This fact, plus the observation that the two samples that have a coverage of $7.79 \mathrm{~kg} / \mathrm{m}^{2}$ have rather different insertion losses indicates that $\eta$ differs from unity for the cellulose samples as well.

The sound insertion loss data obtained with the same samples compressed to different thicknesses provide information as to the values of the exponent $\eta$ for the different materials at different sound frequencies. Figures $12-14$ show the percentage change in insertion loss, versus frequency, for the four types of blown material. Restricting attention to the results at $10 \mathrm{kHz}$, it is seen that the blown bonded fiberglass and the blown rockwool samples exhibited very little dependency of insertion loss on thickness, indicating that for these samples the value of $\eta$ appears to be very near to unity. For the finer-fiber unbonded glass material and, particularly, for the cellulose material which has very small pores, the insertion loss increased as the sample was compressed, indicating a value for $\eta$ that is significantly different from unity.

In order to further explore the effectiveness of using a value of $\eta$ different from unity, a non-linear least squares software package was used to fit equations of the form of Eq. (7) to the experimental data of coverage versus sound insertion loss and sample thickness for the various blown materials. For the two fiberglass materials, the proportionality constant, $K$, was forced to be the same but the bonded and unbonded materials were allowed to have different values for $\eta$. The measured coverage is plotted versus the predicted coverage in Fig. 16. For the bonded fiberglass, the value obtained for $\eta$ was 1.0285 , with 95 percent confidence limits of \pm 0.0013 , while for the unbonded fiberglass $\eta=0.8652 \pm 0.0037$. The residual standard deviations were $0.016 \mathrm{~kg} / \mathrm{m}^{2}$ and $0.052 \mathrm{~kg} / \mathrm{m}^{2}$ for the bonded and unbonded fiberglass, respectively.

A similar procedure applied to the data for rockwool yielded the results plotted in Fig. 17. There is some improvement in comparison to the simple proportionality of Fig. 10 but the value obtained for $\eta$ is not reasonable in terms of the results of the compression test (Fig. 14). In an attempt to predict coverage with less uncertainty, several different equations with linear coefficients were fitted to the experimental data. One of the more successful equations was $W=K \cdot D\left(1+b D+c D^{\prime}\right)$, where $K, b$, and $c$ are constants to be determined and $D^{\prime}$ is the slope of the sound insertion loss versus the logarithm of sound frequency, evaluated at $10 \mathrm{kHz}$ (see Fig. 7). The results of this curve-fitting attempt are shown in Fig. 18. Clearly there is a marked improvement but at the expense of one more constant to be determined. 


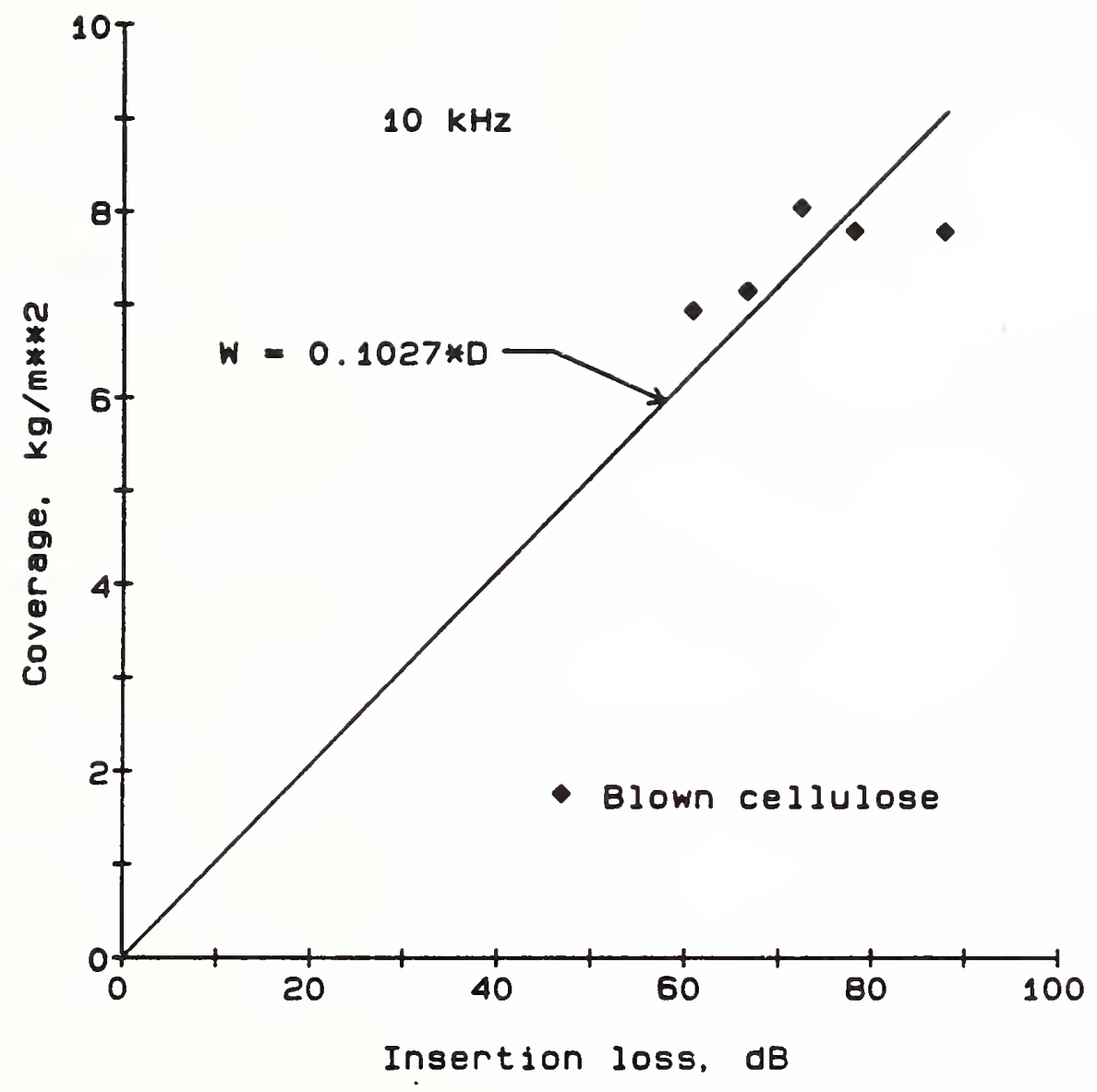

Fig. 11 Measured coverage versus sound insertion loss at $10 \mathrm{kHz}$ for the blown cellulose samples. The equation defines the least-squares straight line fitted to the data and passing through the origin. 


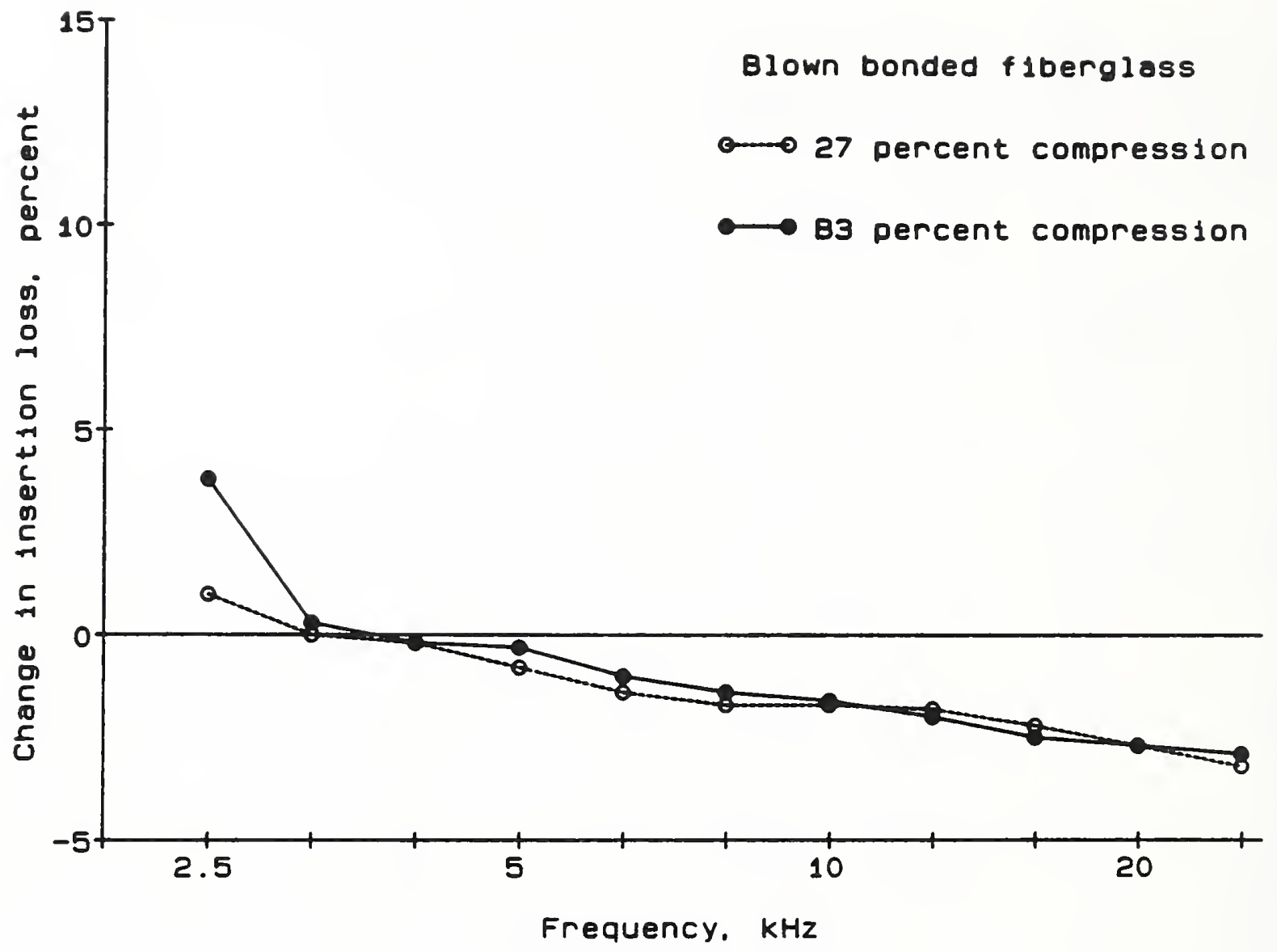

Fig. 12 Percentage change in insertion loss, plotted versus sound frequency, due to compressing a blown bonded fiberglass sample to two different thicknesses. 


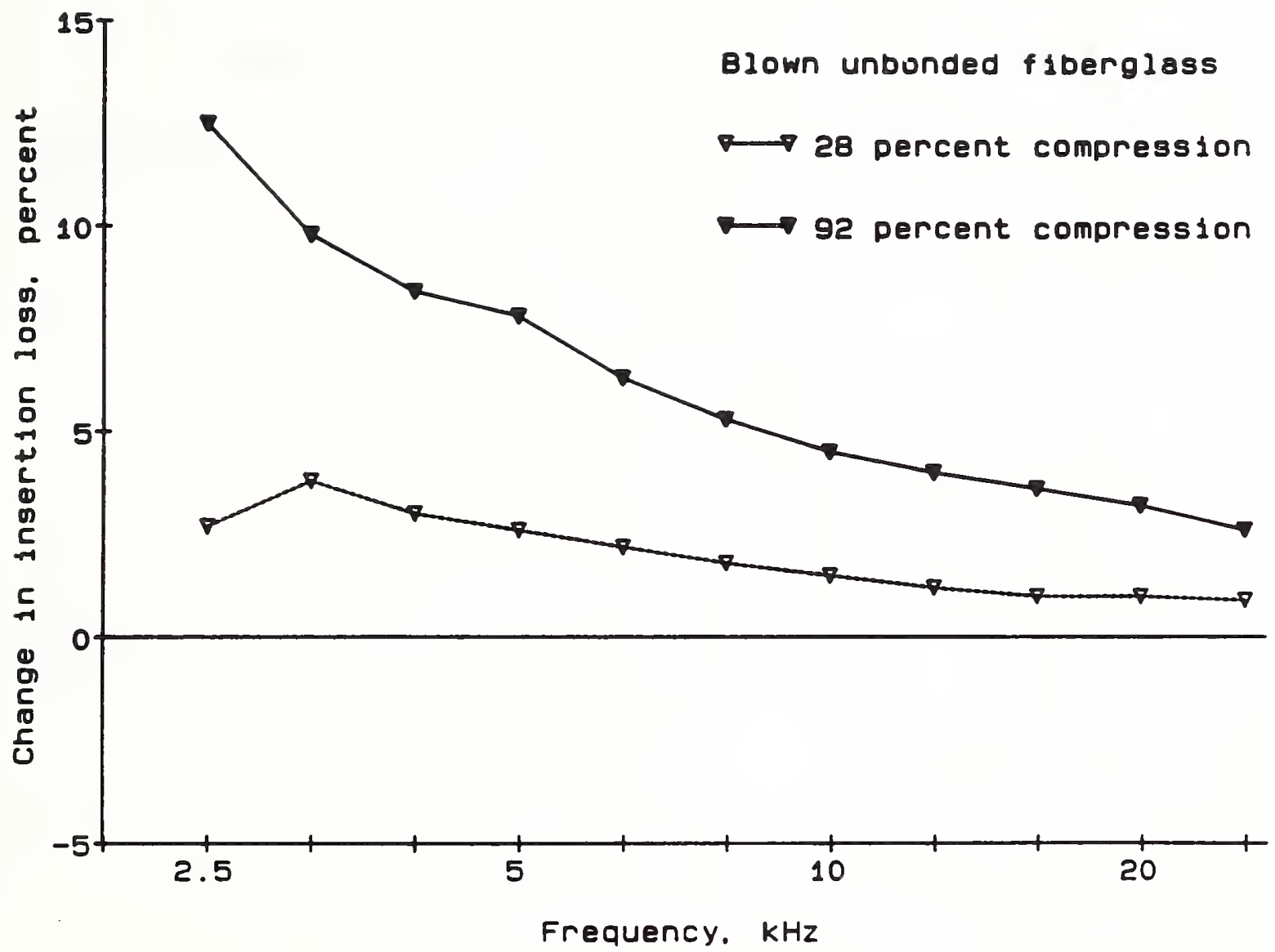

Fig. 13 Percentage change in insertion loss, plotted versus sound frequency, due to compressing a blown unbonded fiberglass sample to two different thicknesses. 


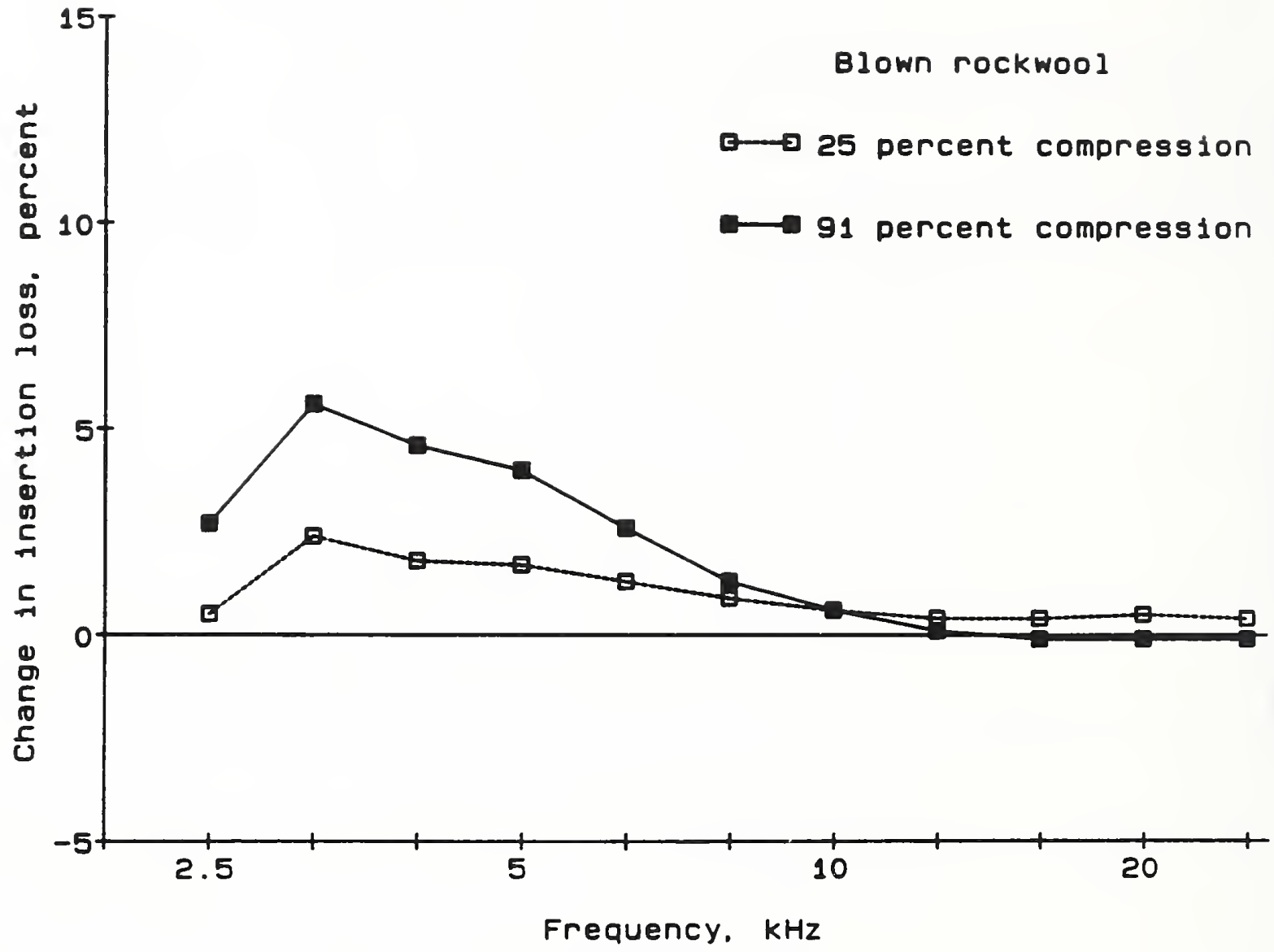

Fig. 14 Percentage change in insertion loss, plotted versus sound frequency, due to compressing a blown rockwool sample to two different thicknesses. 


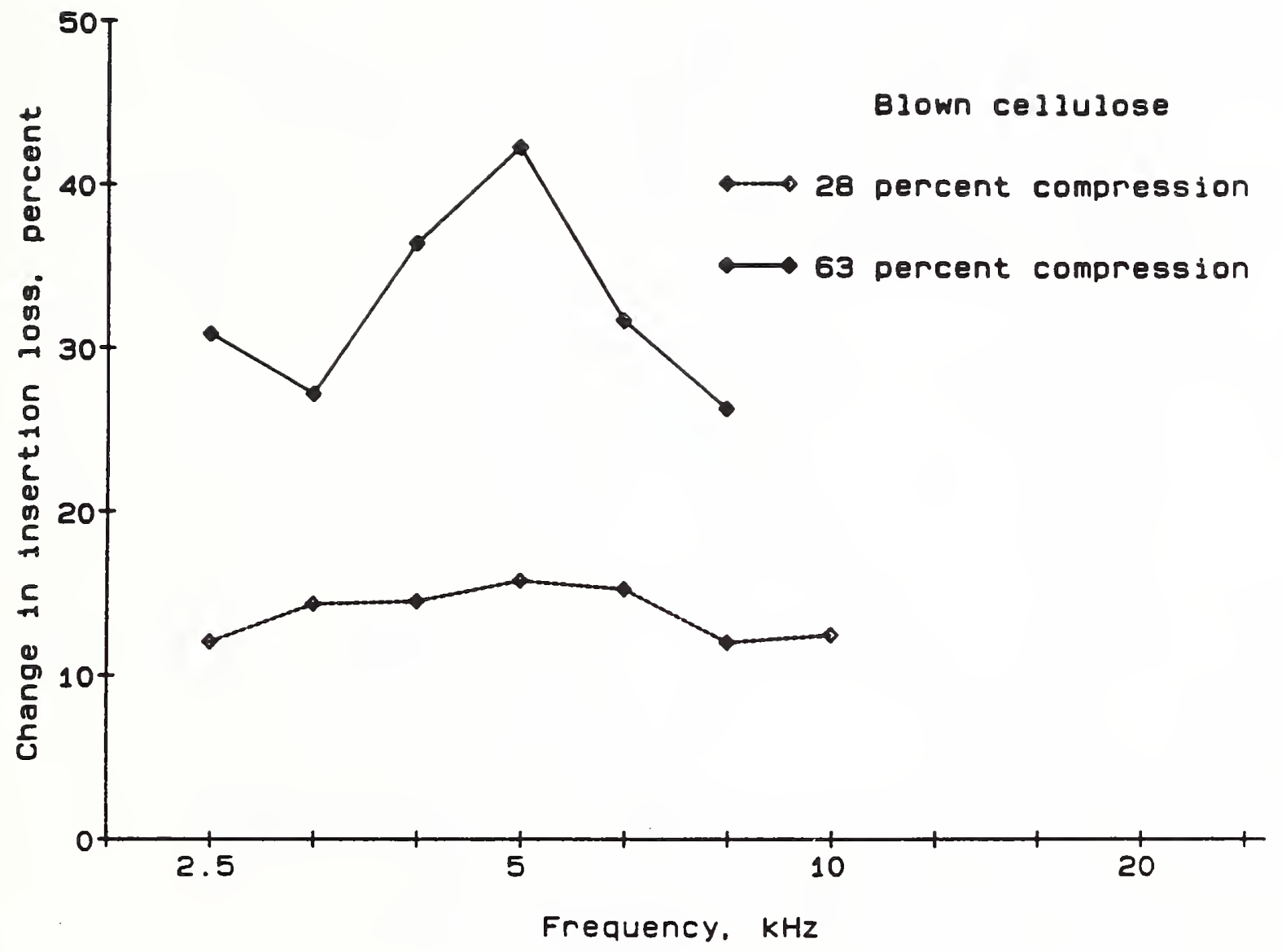

Fig. 15 Percentage change in insertion loss, plotted versus sound frequency, due to compressing a blown cellulose sample to two different thicknesses. 


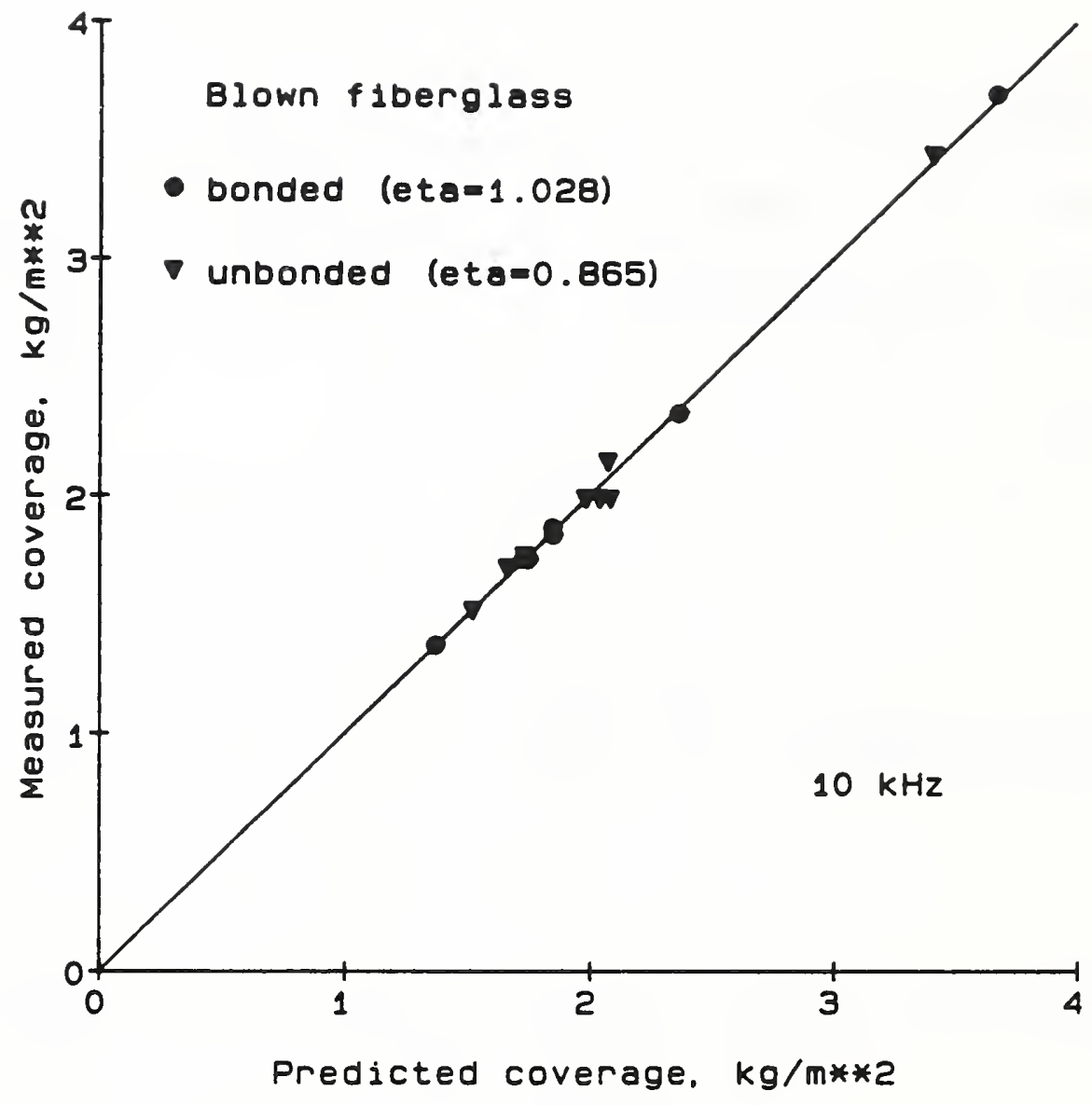

Fig. 16 Measured coverage plotted versus predicted coverage for the blown fiberglass samples, both bonded and unbonded. The prediction equations were of the form of Eq. (7) with a fixed value of $K$ but different values of $\eta$ for the two types of material. 


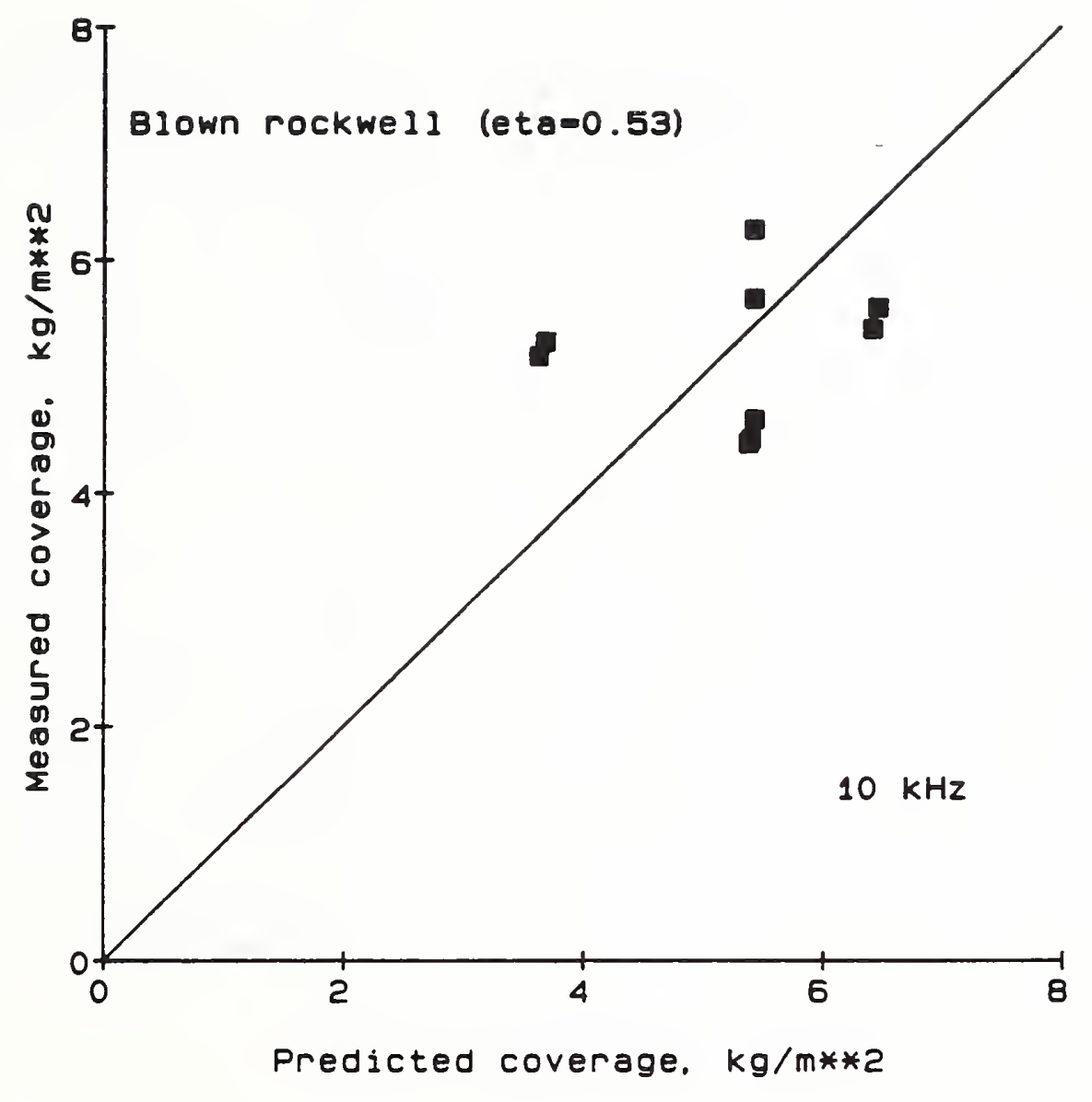

Fig. 17 Measured coverage plotted versus predicted coverage for the blown rockwool samples. The prediction equation was of the form of Eq. (7). 


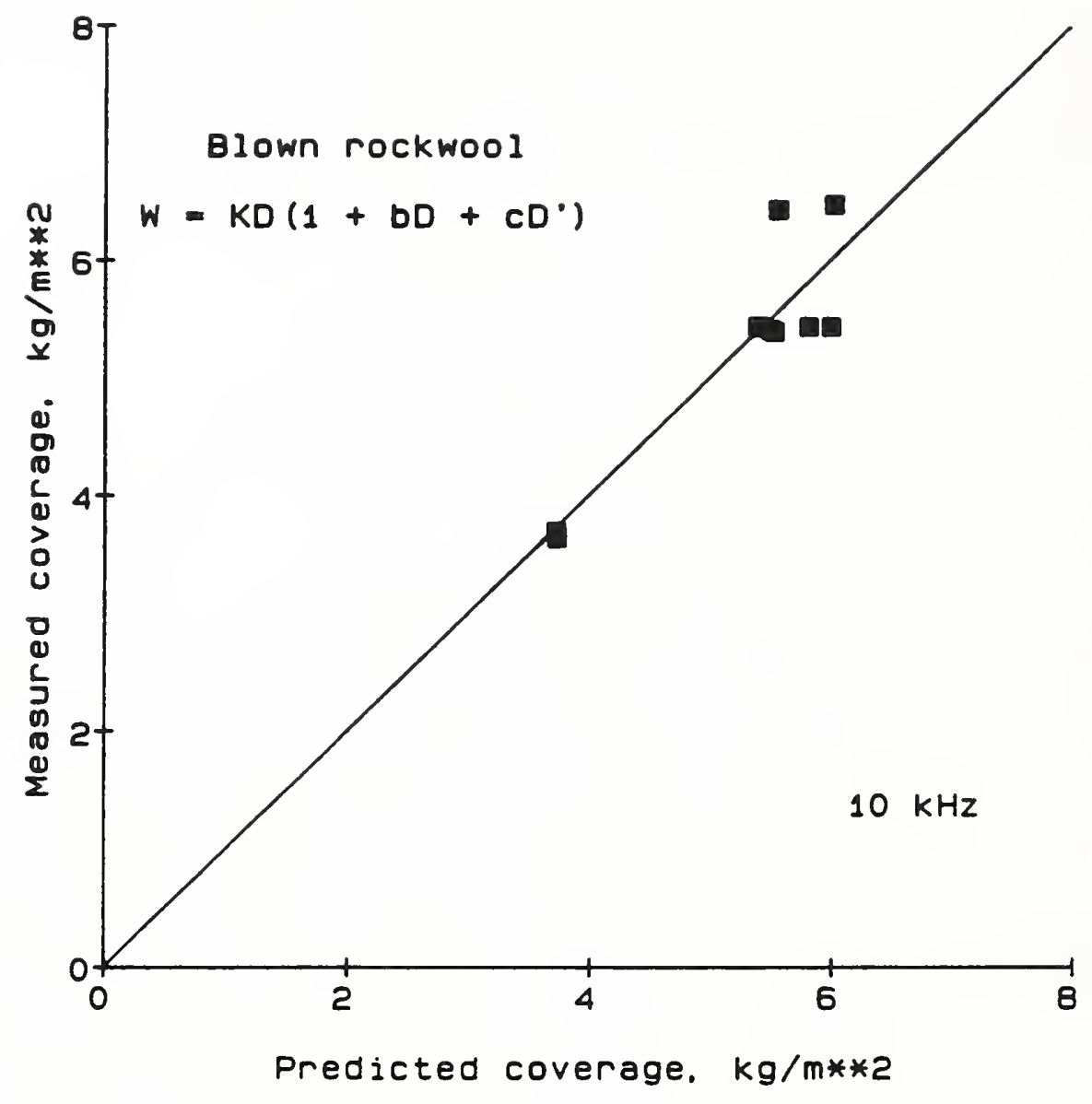

Fig. 18 Measured coverage plotted versus predicted coverage for the blown rockwool samples. The prediction equation is discussed in the text. 
For future work of this nature, it is recommended that the value of $\eta$ be determined directly by compression of a number of samples rather than just one of each material as was done here. It also would be very useful to measure the shot content of each sample after completion of the acoustic tests.

\subsection{Thermal Resistance}

The apparent thermal conductivities at $23.9{ }^{\circ} \mathrm{C}$ for some samples of the roundrobin materials were measured using the NIST 1-meter line-heat-source guarded hot plata. The results of these measurements for the blown materials are illustrated in Figs. 19 and 20. The curves shown are of the form of Eq. (8) and were fitted to the experimental data, yielding values for the constants $A$, $B$, and $C$. These equations were used to compute the thermal resistance of each acoustical test sample from its measured density and thickness.

As indicated following Eq. (9), if the density of the material were constant, the thermal resistance would be simply proportional to the coverage so that if the density were constant and $\eta$ equal to unity, the thermal resistance would simply be proportional to the sound insertion loss. The limited usefulness of such a relationship is evidenced by the results shown in Figs. 21 and 22.

Figures 23, 24, and 25 show the thermal resistance (obtained, as described above, from density and thickness) plotted versus the predicted thermal resistance for blown fiberglass, rockwool, and cellulose, respectively. The predicted thermal resistance was obtained from the measured sound insertion loss and thickness using Eq. (9), with $W$ obtained by the best method of the previous section, $\rho$ obtained from that value of $W$ divided by the measured sample thickness, and $A, B$, and $C$ being the values obtained for the curves in Figs. 19 and 20. The predictions are seen to be very good for fiberglass, not bad for cellulose, and only fair for rockwool. The agreement between observation and prediction for rockwool might have been better if the density of the material has been known exclusive of shot content for both the thermal and the acoustical measurements.

\section{Prospects for Field Use}

Based upon the results presented above, the use of sound insertion loss measurements to predict the coverage or the thermal resistance of loose-fill insulations appears promising, particularly for fiberglass materials. The extension of the above-described laboratory work to field conditions will be challenging but there do not appear to be any insurmountable difficulties. (It should be noted that regardless of whether a circular cutter, a thermal technique, or an acoustizal technique is used, variations in installed thickness and coverage will require measurements at a large number of locations in order to achieve statistical reliability.)

Two different approaches [9] appear feasible for using sound waves for in-situ evaluation of attic insulation coverage and thermal resistance. One approach, shown in Fig. 26, would be to position a transducer above the insulation and measure the (pulsed) signal that has passed downward through the insulation, 


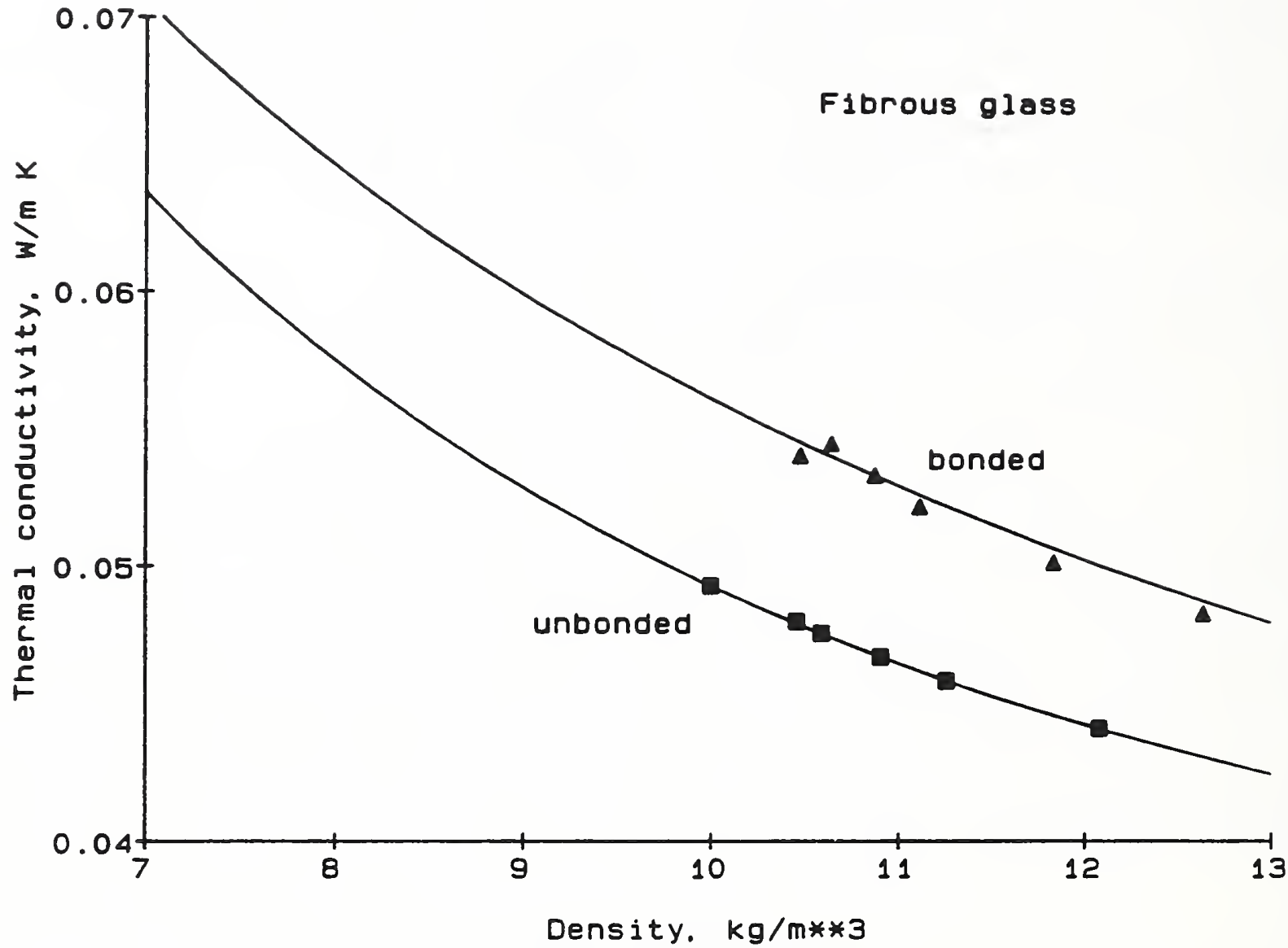

Fig. 19 Thermal conductivity versus installed density for the two types of blown fiberglass material. The data were obtained in the NIST 1-meter, line-heat-source guarded hot plate. The curves (of the form of $\mathrm{Eq} .(8)$ ) were used to estimate, from measured densities, the thermal conductivities of the samples used in the acoustir tests. For bounded fiberglass, the equation of the curve is $\lambda=$ $0.0270-0.000272 \rho+0.319 / \rho$, in the units shown in the figure. For unbonded fiberglass, the curve is described by $\lambda=0.0053+0.000623 \rho+0.378 / \rho$. 


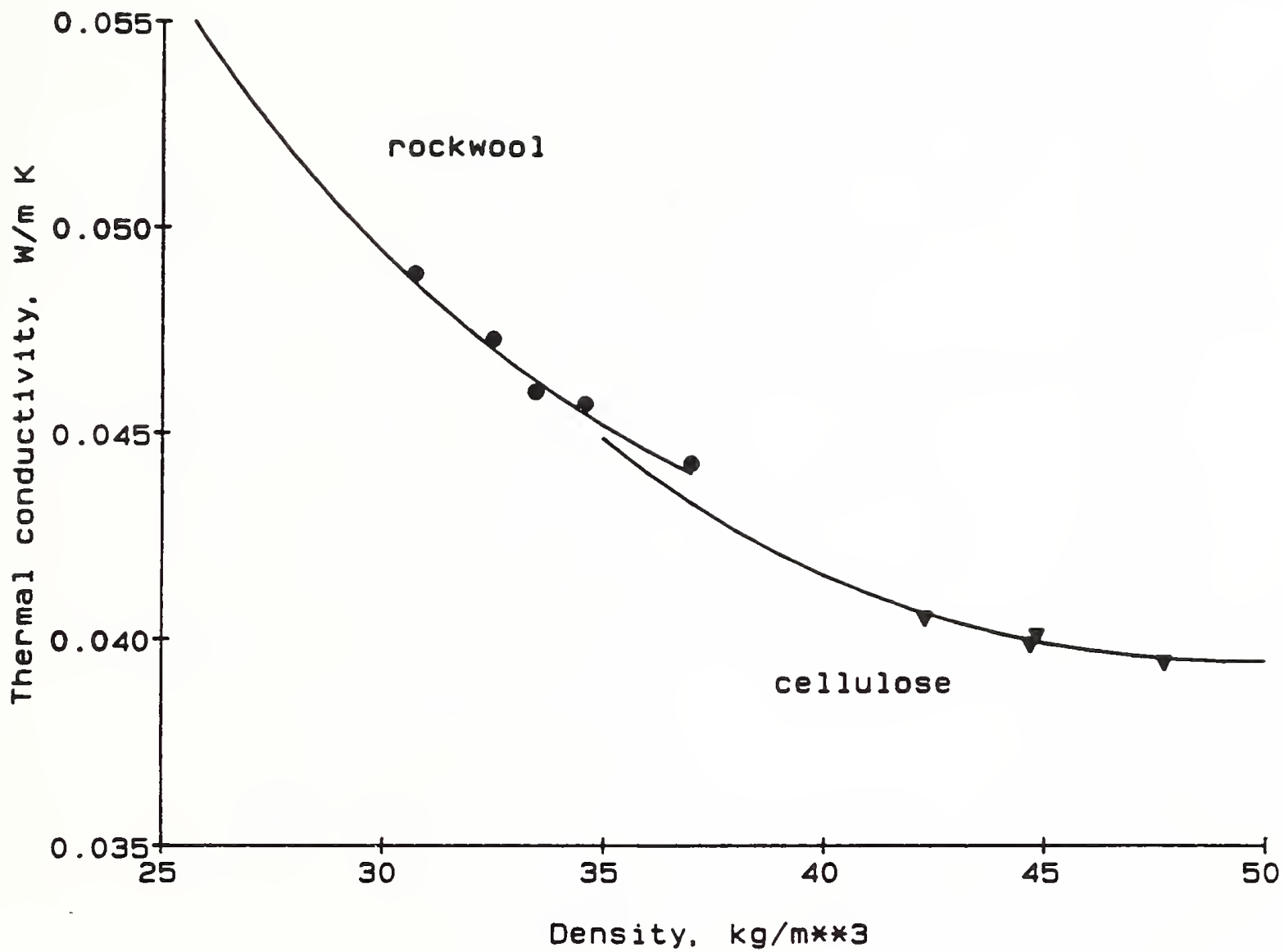

Fig. 20 Thermal conductivity versus installed density for blown rockwool and blown cellulose. The data were obtained in the NIST 1-meter, line-heat-source guarded hot plate. The curves, of the form of $\mathrm{Eq}$. (8), were used to estimate, from measured densities, the thermal conductivities of the samples used in the acoustic tests. For rockwool, the equation of the curve is $\lambda=-0.0110+0.000475 \rho+$ $1.382 / \rho$, in the units shown in the figure. For cellulose, the curve is described by $\lambda=-0.0452+0.000878 \rho+$ $2.112 / \rho$. 


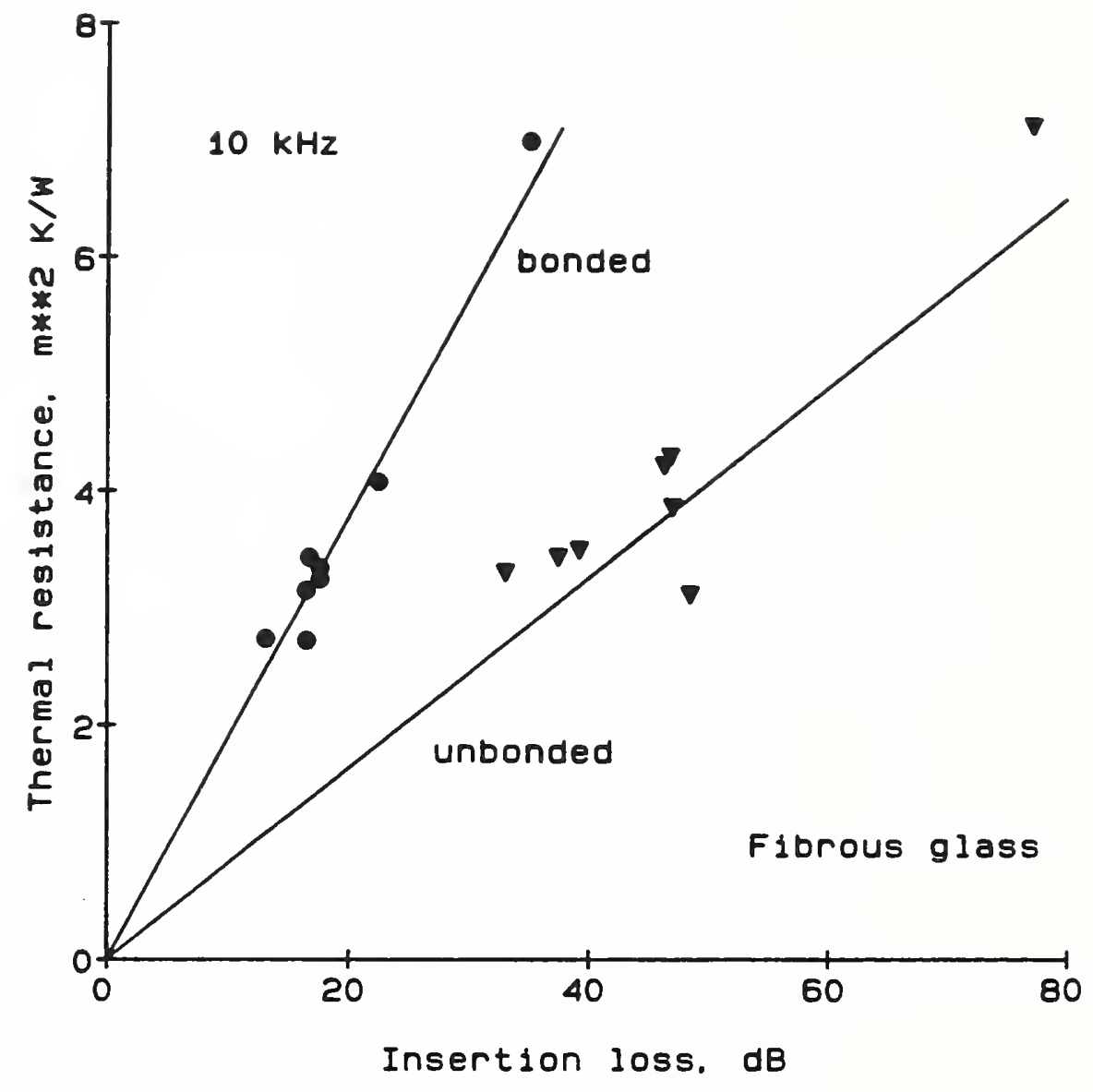

Fig. 21 Thermal resistance versus sound insertion loss, at $10 \mathrm{kHz}$, for the blown bonded and unbonded fiberglass samples. Each line fitted to the data represents the least-squares straight line passing through the origin. 


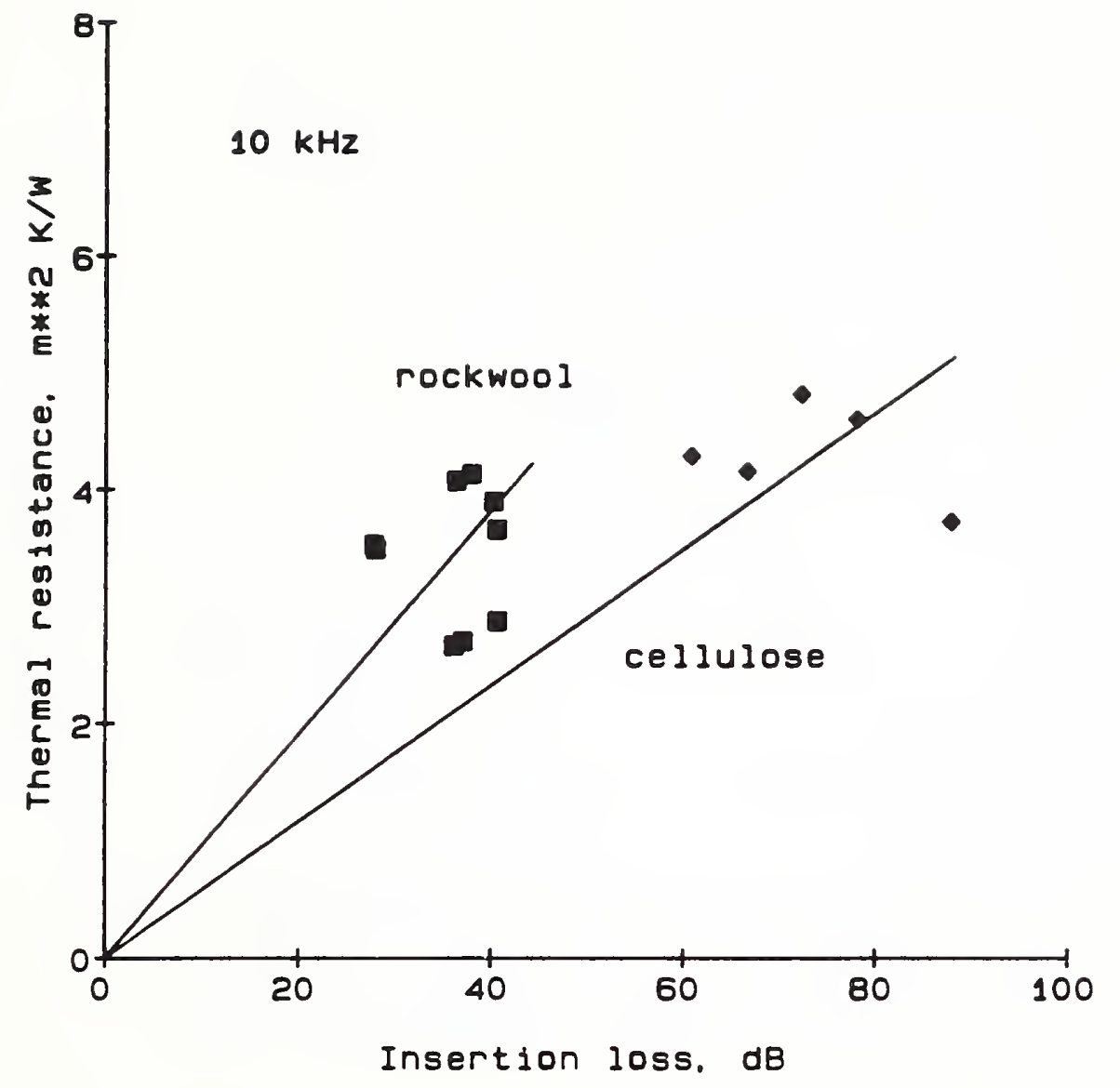

Fig. 22 Thermal resistance versus sound insertion loss, at $10 \mathrm{kHz}$, for the blown rockwool and cellulose samples. Each line fitted to the data represents the least-squares straight line passing through the origin. 


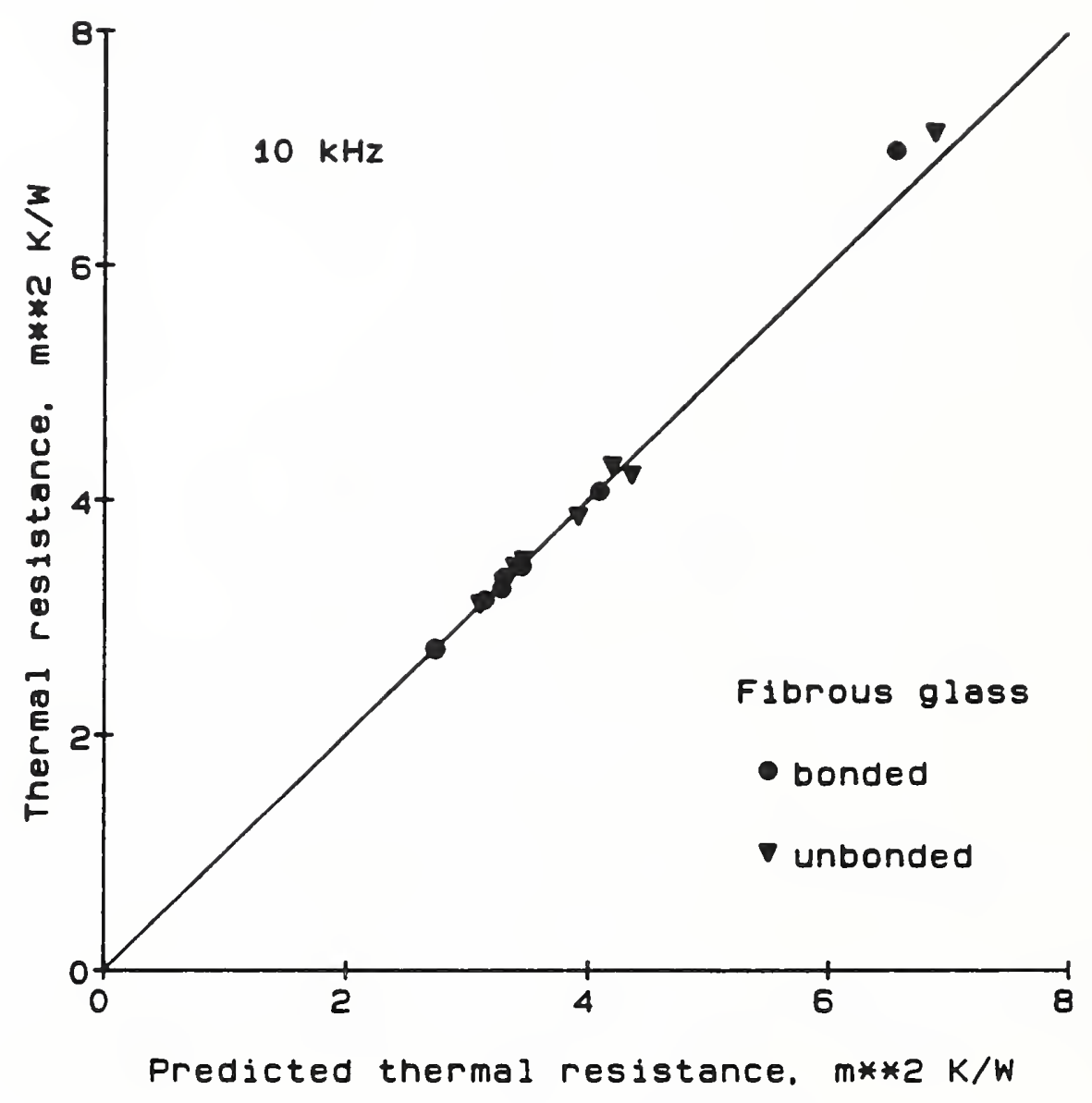

Fig. 23 Thermal resistance computed from density and thickness versus thermal resistance predicted from sound insertion loss and thickness for the blown bonded and unbonded fiberglass samples. 


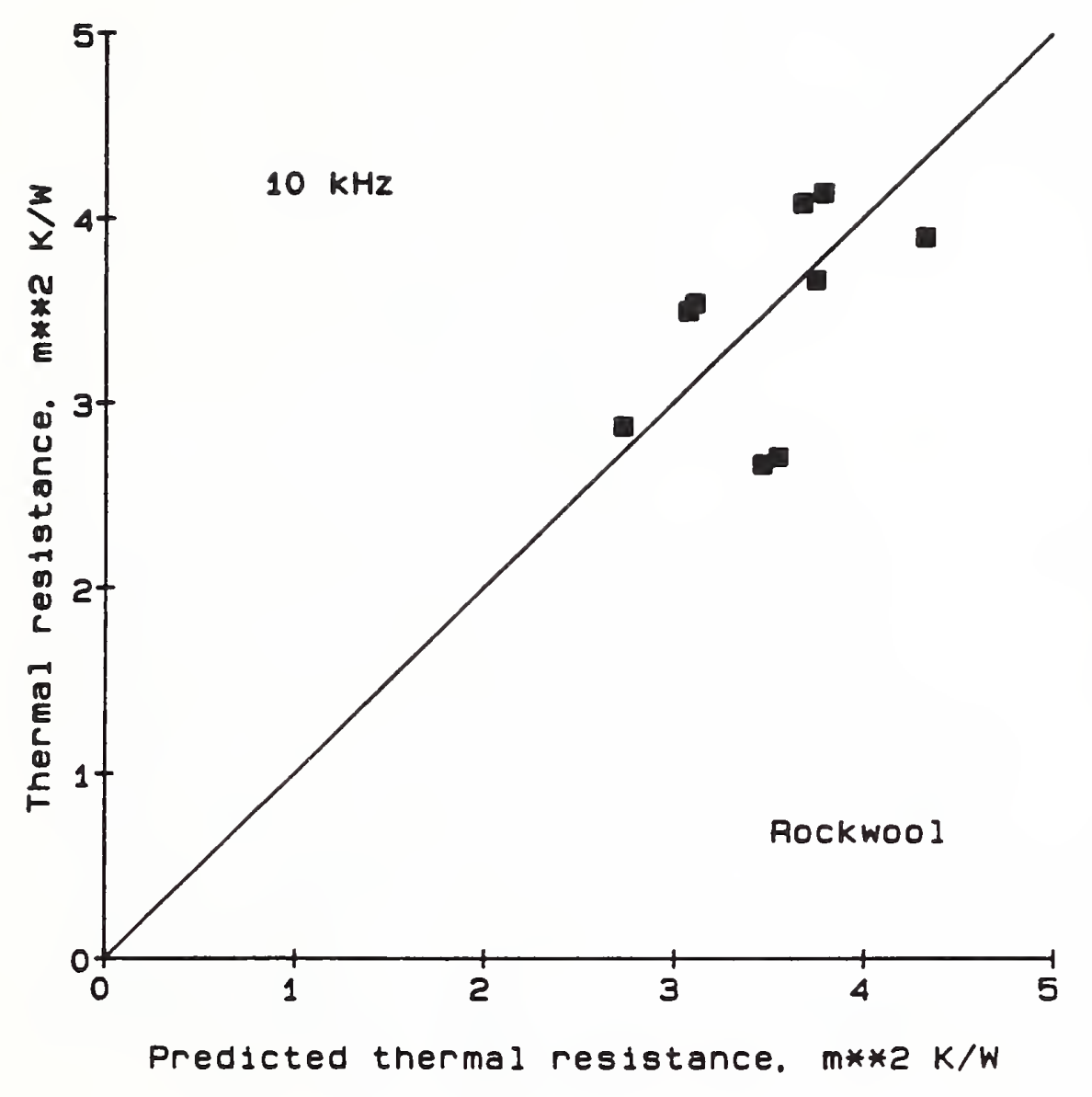

Fig. 24 Thermal resistance computed from density and thickness versus thermal resistance predicted from sound insertion loss and thickness for the blown rockwool samples. 


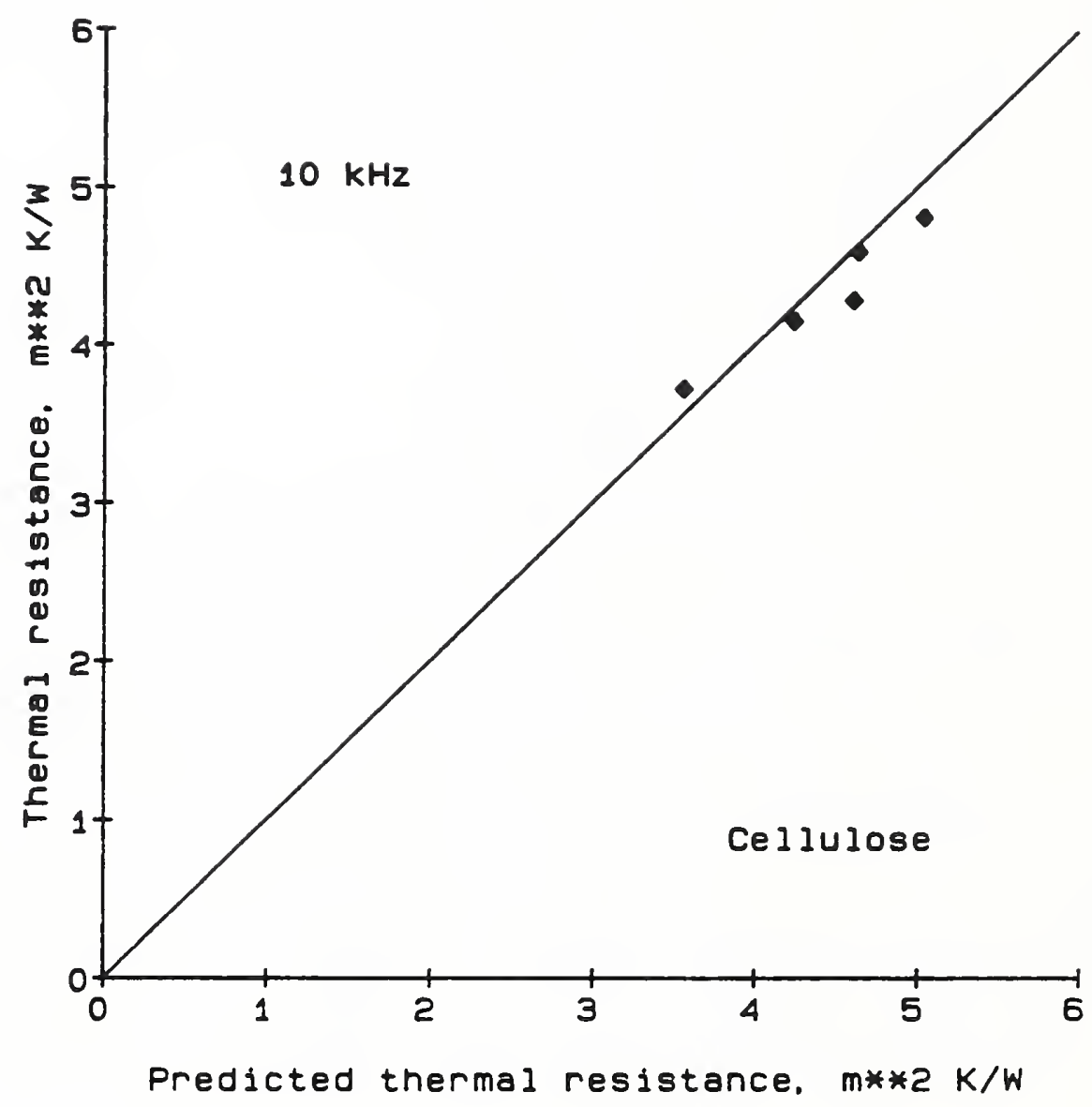

Fig. 25 Thermal resistance computed from density and thickness versus thermal resistance predicted from sound insertion loss and thickness for the blown cellulose samples. 


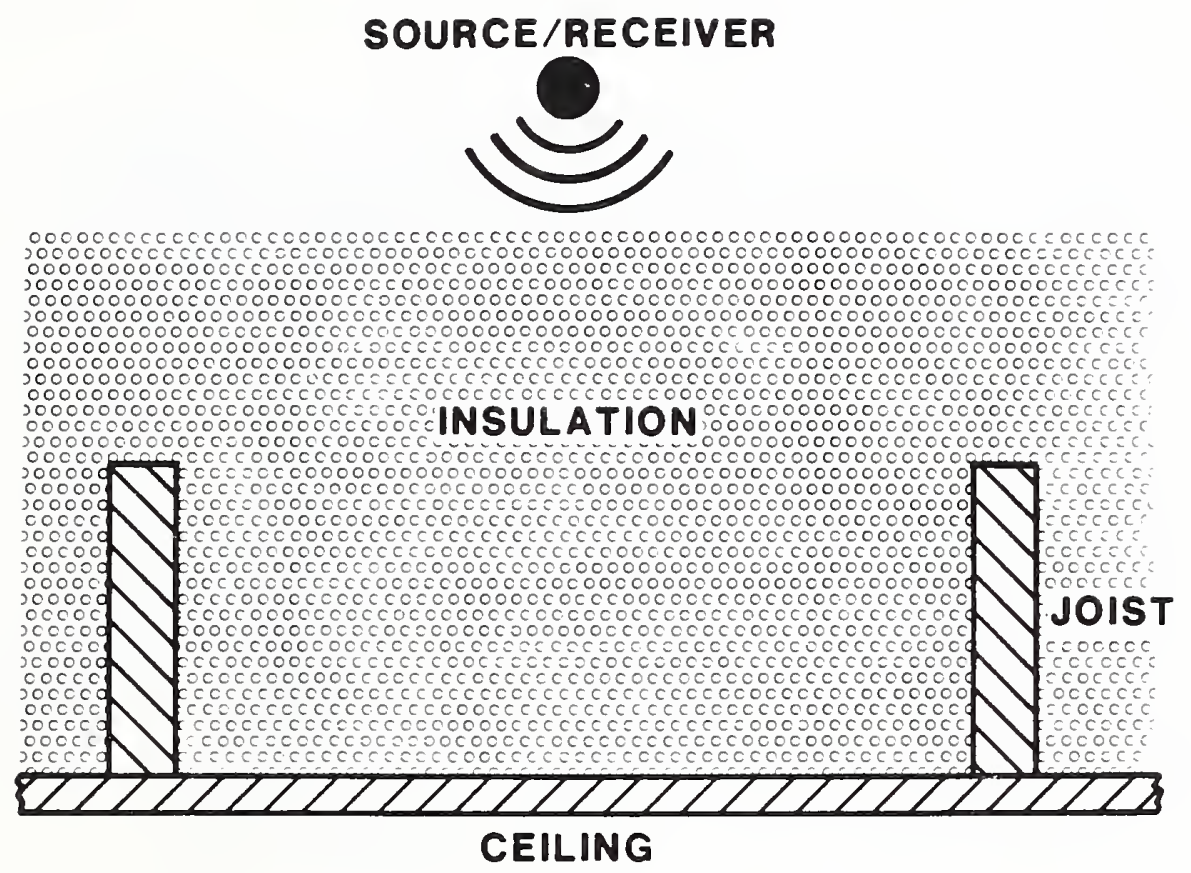

Fig. 26 One experimental configuration for field measurements of the coverage or thermal resistance of blown-in-place attic insulation. A pulse of sound from a transducer above the insulation passes downward through the insulation, reflects off the upper side of the ceiling, and returns through the irsulation to the transducer. 


\section{ATTIC AIR}

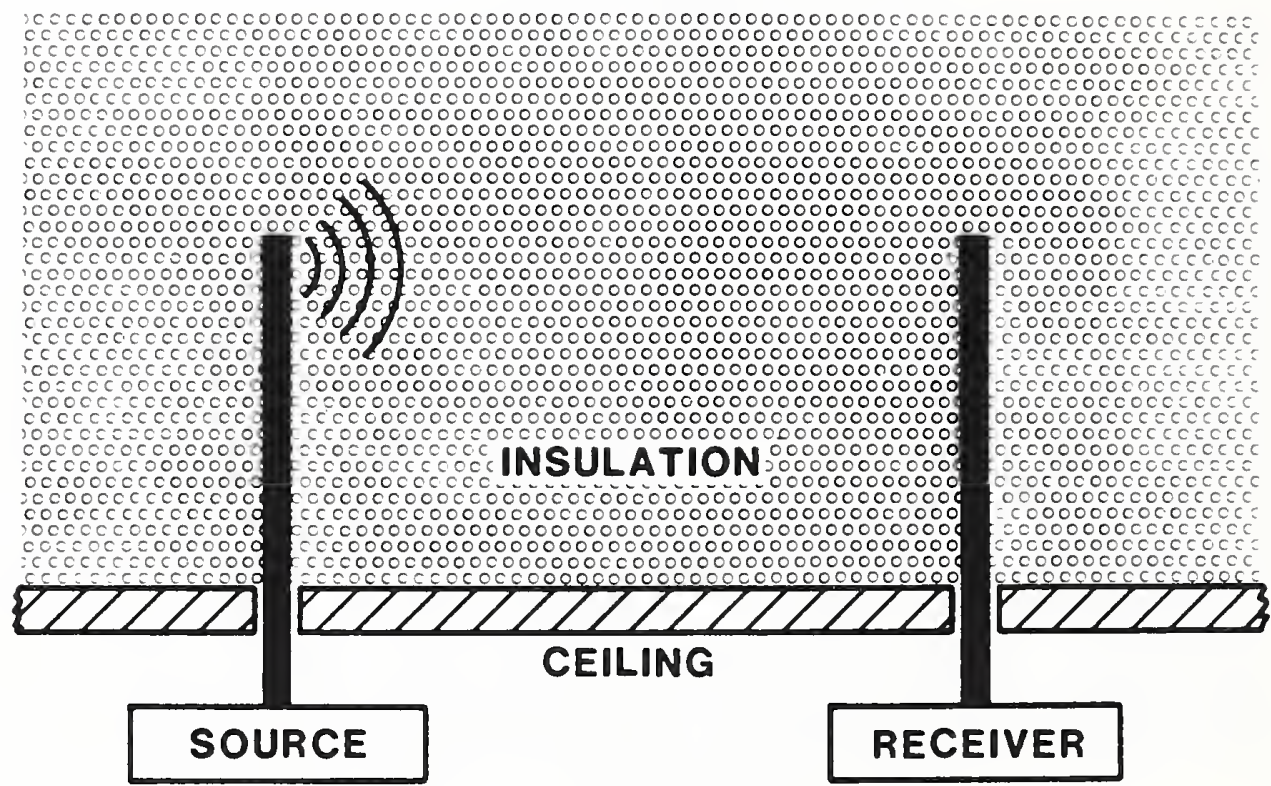

Fig. 27 Experimental configuration for field measurements of the density or thermal conductivity of blown-in-place attic insulation when it is not practical to enter the attic space. A sound source probe and a sound receiving probe are each inserted through small holes in the ceiling and measurements made as describad in the text. 
reflected from the top of the ceiling, and passed upward through the insulation and back to the transducer. The source/receiver shown in Fig. 26 could include a parabolic reflector, as used in the present study, or could simply be an extended transducer. A second approach, illustrated conceptually in Fig. 27, would be to position a transmitter and a receiver a fixed distance apart within the insulation.

The technique of using a vertically oriented system such as depicted in Fig. 26, with the transducer in the attic space operating in a send-receive, or pulse-echo, mode, would have the advantage of requiring no penetration holes in the ceiling. It has the disadvantage, however, of requiring access to the attic space, with the probe suspended from a "fishing pole" operated from the access hole or the operator actually entering the attic. A further complication with this technique is the large attenuation associated with the sound passing twice through a large thickness of insulation; this difficulty can be dealt with by using sound of lower frequency than is reported in the present study.

The technique of using two probes inserted through small holes in the ceiling to the same height within the insulation, so that the sound waves travel parallel to the ceiling, has several advantages. It should be possible to determine the insulation depth by monitoring the signal as the probe pair is moved upward through the insulation layer. When the signal matched a pre-calibrated value established for an open air path, the boundary between the upper surface of the insulation and the attic air would be determined. By measuring the signal as the probes are moved upward through the insulation, the insulation density as a function of elevation (depth) could be determined. This technique would have the disadvantage of requiring that two small holes be drilled through the ceiling at each location where the density profile and the depth of the insulation need to be ascertained. However, these holes would be very small and could easily be repaired upon completion of measurements.

It is important to reiterate the need to know the relationship between sound insertion loss and coverage for the particular material that is installed in an attic. If the insulation is, for example, a virgin glass wool of known origin, it should be possible to use "standard" parameters for that material. For unknown materials, or materials that exhibit considerable variability, the appropriate parameters should be determined for the particular lot of material.

Probably the easiest way to obtain the appropriate parameters, when access to the attic is possible, would be to measure the sound insertion loss at a few locations near the access hole to the attic, both with the insulation at its installed thickness and with the insulation compressed to, say, half its installed thickness. A circular-cutter and depth gage could then be used to determine the coverage and thickness at the same locations where the acoustical measurements were made. From these data, the parameters $\mathrm{K}$ and $\eta$ in Eq. (7) could be obtained for the specific installed insulation.

The acoustical technique could then be used to map the sound insertion loss at a large number of locations in the attic. These data (plus the nominal thickness, since $W$ is only weakly dependent upon $l$ ) could then be used to compute the coverage at each location where sound insertion loss was measured. In this 
way the coverage could be mapped without the destructive effects of taking numerous circular-cutter samples throughout the attic.

If it is desired to obtain the thermal resistance as well as the coverage, it would be necessary to know the relationship between thermal conductivity and density for the particular type of insulation. Usually such data should be available from the insulation manufacturer.

\section{Conclusions}

It is shown that the coverage, $W$, of installed insulation in an attic is related to the sound insertion loss, D, and thickness, $\ell$, by the expression

$$
\mathrm{W}=\mathrm{K} \cdot \mathrm{D}^{\eta} \ell^{1-\eta},
$$

where $\mathrm{K}$ and $\eta$ are material-dependent constants. The parameter $\eta$ will have a value not too different from unity so that $l$ need not be known very accurately in order to obtain $W$. For the special case where $\eta=1$, this equation reduces to $\mathrm{W}=\mathrm{K} \cdot \mathrm{D}$, i.e., the coverage is proportional to the sound insertion loss.

The thermal resistance, $R$, of installed insulation in an attic is related to the sound insertion loss, the thickness, the density, $\rho$, and the thermal conductivity, $\lambda=\lambda(\rho)$, by the expression

$$
\mathrm{R}=\frac{\ell}{\lambda}=\frac{\mathrm{W}}{\rho \lambda}=\frac{\mathrm{K} \cdot \mathrm{D}^{\eta} \ell^{1-\eta}}{\rho \lambda}
$$

If the density of the sample is constant so is the denominator of Eq. (12) and the thermal resistance is proportional to the coverage. For the special case where the density is constant and, also, $\eta=1$, the thermal resistance is proportional to the sound insertion loss. For the case where the installed density is variable and unknown, the density can be estimated from

$$
\rho=\mathrm{K} \cdot(\mathrm{D} / \ell)^{\eta} ;
$$

this value of $\rho$ can be used to obtain the denominator of Eq. (12), provided the dependence of thermal conductivity on density is known for the particular type of insulation. In this manner the thermal resistance can be related to the measured sound insertion loss and the approximate sample thickness.

An apparatus was designed and constructed to carry out laboratory measurements of the sound insertion loss of samples of blown insulation. In this apparatus the insulation sample is held in a wood-sided basket with a screen bottom to allow passage of the beam of sound through a central region of the sample. The instrumentation used provided measurements of sound insertion loss as a function of frequency from 2.5 to $25 \mathrm{kHz}$.

In addition to data on sound insertion loss, data were obtained on the coverage, density, and thickness of the insulation blown into each sample basket. The test materials investigated were a fiberglass blanket (the only material 
not blown), a bonded fiberglass, an unbonded fiberglass, a rockwool, and a cellulose. For each material, samples were prepared of varying thickness, coverage, and density. For one sample of each of the blown insulations, a value of $\eta$ was obtained by measuring sound insertion loss as the sample material was compressed to different thicknesses.

The experimental data for each material were analyzed to examine the relationship between coverage and sound insertion loss at $10 \mathrm{kHz}$. For the blown fiberglass samples, the coverage was found to be reliably predicable from sound insertion loss and sample thickness, using Eq. (11) with a single value of $\mathrm{K}$ but with different values of $\eta$ being used for the two types of fiberglass. The correlation between $W$ and $D$ was found to be poor for the rockwool samples, presumably because rockwool includes a rather large component of shot and fused fiber that affects $W$ but not $D$. For cellulose, the correlation between $W$ and $D$ was much better than for rockwool but not so good as for fiberglass.

A limited number of measurements were made of the thermal conductivity of each material as a function of density. Empirical equations fitted to these data were used to estimate, from measured density and thickness, the thermal resistance of the other samples on which acoustical, but no thermal, measurements were made. The thermal resistance was also predicted, using Eqs. (12) and (13), from the measured sound insertion loss and sample thickness, also using coefficients from the empirical equations fitted to the experimental data for thermal conductivity versus density. The correlation between thermal resistance (as computed from measured thickness and density) and the predicted (from sound insertion loss and thickness) thermal resistance was found to be very good for fiberglass, not bad for cellulose, and only fair for rockwool. The agreement might have been better for rockwool if the density of each sample had been known exclusive of shot content for both the acoustical and the thermal measurements.

Based on the results presented in this report, it is concluded that the use of sound insertion loss measurements to predict the coverage or thermal resistance of insulation appears promising, particularly for fiberglass materials. The extension of this technique to field measurements will be challenging but there do not appear to be any insurmountable difficulties. Two different approaches are described for in-situ acoustical measurements, one approach that yields coverage and $R$-value and another approach that is more closely tied to density and thermal conductivity. For either of these techniques it is necessary to know the relationship between coverage (or density) and sound insertion loss for the particular material that is installed. If it is desired to obtain thermal resistance (or thermal conductivity), it is necessary to know the relationship between thermal conductivity and density for the particular type of insulation.

\section{Acknowledgments}

We thank H. G. Woten, President of Unisul Inc, for the loan of the blowing machine; R. S. Graves of Oak Ridge National Laboratory for sharing his experience in the use of the blowing machine; $R$. D. Adams of Owens Corning Fiberglas Corp. for arranging the availability of the ASTM round robin materials and 
for providing us with data on fiber diameters; W. M. Edmunds of Owens Corning Fiberglas Corp. and J. F. Kimpflen of Certain-teed Corp. for arranging to provide guidance on blowing and handling of loose-fill insulations; $T$. A. Somers of the NIST Center for Building Technology (CBT) for carrying out the thermal conductivity measurements; and R. R. Zarr of CBT for supervising the thermal conductivity measurements and assisting with blowing the test samples.

\section{References}

[1] Private communication between Michael Baum, of NIST, and Eunice Baros and Nicky Clark, of the Florida Attorney General's Office of Consumer Affairs, April 1987 .

[2] Private communication between Michael Baum, of NIST, and Bill Cloud of the Georgia Governor's Office, April 1987.

[3] ASTM C687-85, Standard Practice for Determination of the Thermal Resistance of Loose-fill Building Insulation (American Society for Testing and Materials, Philadelphia, 1985).

[4] Letter, dated December 7, 1984, from Kenneth D. Mentzer, Staff Vice President of the Mineral Insulation Manufacturers Association, to Ernest Ambler, Director of the National Bureau of Standards.

[5] Delany, M. E. and Bazley, E. N., "Acoustical Properties of Fibrous Absorbent Materials," Appl. Acoustics 3, 105-116 (1970).

[6] Bies, D. A., "Acoustical Properties of Porous Materials," pp. 245-269 in Noise and Vibration Control, L. L. Beranek, Ed. (McGraw-Hill, New York, 1971).

[7] ASTM C167-82, Standard Test Methods for Thickness and Density of Blanket or Batt Thermal Insulation (American Society for Testing and Materials, Philadelphia, 1982).

[8] Adams, R. D. and Hust, J. G., "An Intralaboratory Comparison of the ASTM C-687 Loose Fill Insulation Test Procedure," in Proc. Symposium on Insulation Materials, Testing and Applications, ASTM STP 1030, D. L. McElroy and J. F. Kimpflen, Eds. (American Society for Testing and Materials, Philadelphia, in press).

[9] Blessing, G. V., and Flynn, D. R., "Acoustic Evaluation of Thermal Insulation," U.S. Patent 4,672,851, June 16, 1987. 
NBS.114A (REV. 2-BC)

U.S. DEPT. OF COMM.

BIBLIOGRAPHIC DATA

SHEET (See instructions)

1. PUBLICATION OR

REPORT NO.

NISTIR $88-3882$
2. Performing Organ. Report Noy 3. Publication Date

April 1989

4. TITLE AND SUBTITLE

An Acoustical Technique for Evaluation of Thermal Insulation

5. AUTHOR(S)

Danlel R. Flynn, David J. Evans, Thomas W. Bartel

6. PERFORMING ORGANIZATION (If joint or other thon NBS, see instructions)

7. ContracV Grant No.

MATIONAL BUREAU OF STAMDARDS

DEPARTMENT OF COMMERCE

WASHINGTON, D.C. 20234

3. Type of Report \& Period Covered

9. SPONSORING ORGANIZATION NAME AND COMPLETE ADDRESS (Street. City, Stote, ZIP)

Mineral Insulation Manufacturers Assoc.

Office of Buildings \& Community Systems

1420 King Street

Alexandria, VA 22314

Bullding Systems Division

U.S. Dept. of Energy

Germantown, MD 20874

Under Contract $D E-A C 05-840 B 21400$

10. SUPPLEMENTARY NOTES

with Martin Marietta Energy Systems Inc

Document describes a computer program; SF-185, FIPS Software Summary, is attached.

11. ABSTRACT (A 200-word or less foctual summory of most significont informotion. If document includes o significont bibliogrophy or literoture survey. mention it here)

A laboratory apparatus has been constructed that enables rapid measurement of the sound insertion loss of a sample of insulation as a function of frequency. An extensive series of measurements of the sound insertion losses associated with blown samples of fiberglass, rockwool, and cellulose has been completed; the results of these acoustical measurements are highly correlated with coverage (mass per unit area) and thermal resistance (R-value). An investigation is planned to extend the acoustical techniques used in the laboratory apparatus to in-situ determination of the sound transmission loss through thermal insulation installed in attics. Two possible approaches to such field measurements are described.

12. KEY WORDS (Six to twelve entries: olphobeticol order: copitalize only proper nomes; ond seporate key words ty semicolons; acoustics; attic insulation; heat flow; heat transfer; insulation; non-destruction evaluation; non-destructive testing; sound attenuation; sound propagation; thermal conductivity; thermal insulation; thermal resistance

13. AVAILABILITY

X Unlimited

Z For Official Distribution. Do Not Release to NTIS

Order From Suderintendent of Documents, U.S. Government Printing Office, Washington, D.C. 20402.

X Order From National Technical Information Service (NTIS), Springfield, VA. 22161
14. NO. OF

PRINTED PAGES

46

15. Price

$\$ 12.95$ 





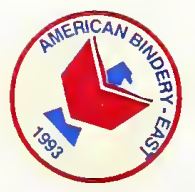


